\title{
ALLGEMEINE RECHTSGRUNDSÄTZE IN DER BUDDHISTISCHEN ORDENSVERFASSUNG (VINAYA)
}

\author{
Von Hellmuth Hecker
}

$\mathrm{Zu}$ den ältesten Dokumenten der Menschheit, die das Zusammenleben einer Gemeinschaft in rechtlicher Form regeln, gehört die Verfassung des buddhistischen Ordens, der sog. Vinaya. Die Vorschriften des Vinaya behandeln alle Gebiete, die damals im Orden einer rechtlichen Regelung bedurften. Die Frage, wie sich die damaligen Vorschriften zu entsprechenden Rechtsformen unserer Sozialordnung verhalten, soll in der folgenden Untersuchung an einigen zentralen Komplexen geprüft werden, nämlich an Strafausschließungsgründen, Mitgliedschaftsverhältnissen und Streitschlichtung. Dabei wird zu zeigen sein, in wie hohem Maße die Regelungen auf diesen drei Gebieten vernünftigen rechtspolitischen Erwägungen entsprechen und Rechtsgrundsätze von allgemeiner Bedeutung widerspiegeln. Da der Vinaya noch nicht ins Deutsche übersetzt ist $^{1}$ und $\mathrm{da}$ indologische Arbeiten dazu nur spärlich$^{2}$, juristische dagegen überhaupt nicht vorliegen ${ }^{3}$, bedarf es zur Verständlichmachung einiger hinleitender Ausführungen zum Hintergrund dessen, was wir mit Vorbehalt „buddhistisches Kirchenrecht" ${ }^{4}$ nennen mögen.

\subsection{Entstehung des Vinaya}

Als der Buddha Gotama im 6. vorchristlichen Jahrhundert - über die genaue Datierung seiner Lebenszeit gehen westliche und östliche Auffassungen auseinander begann, seine Lehre darzulegen, gab es zunächst noch keine Ordensverfassung. Es galt als selbstverständlich, daß die in den Mönchsorden des Buddha Eintretenden gewisse Regeln einhielten, die sich einerseits aus der indischen asketischen Tradition, andererseits aus dem Tugendteil der Lehre ergaben. Erst als der Orden größer wurde, waren zunehmende Regelungen erforderlich. Während die ersten Mitglieder des Ordens aus innerer Berufung eintraten, führten später oft äußerliche Motive dazu. So heißt es in einem Text ${ }^{5}$ :

„Wenn die Wesen sich verschlechtern, wenn die wahre Lehre schwindet, dann gibt es mehr der Ordensregeln, aber weniger erlangen höchste Vollendung. Nicht eher gibt der Meister den Jüngern die Regeln an, bis da nicht manche auf Trieben beruhende Dinge im Orden offenbar werden. Sobald nun

1 Vollständige englische Übersetzung von I. B. Horner, The Book of Discipline (Vinaya-pitaka), 6 Bde, London 1938-1966. Auf deutsch liegt allein eine Teilübersetzung einer Sanskritfassung (s. u.) vor: Valentina Rosen, Der Vinayavibhanga zum Bhiksuprātimoska der Sarvādivādins. Sanskritfragmente nebst einer Analyse der chinesischen Übersetzung, Ost-Berlin 1959.

2 E. Frauwallner, The earliest Vinaya and the beginnings of Buddhist Literature, Rom 1956 (das Werk ist auf deutsch geschrieben, wurde aber nur in englischer Ubersetzung veröffentlicht). Er meint, der Vinaya enthalte keine allg. Prinzipien und sei ziemlich künstlich (S. 130), oder man sei damals gar unfähig zu solchen allg. Prinzipien gewesen (S. 143).

Sukumar Dutt, Buddhist monks and monasteries of India. Their history and their contribution to Indian culture, London 1962.

Sukumar Dutt, Early Buddhist monachism, London, 1. Aufl. 1924, 2. Aufl. 1960.

H. Härtel, Karmavācānā: Formulare für den Gebrauch im buddhistischen Gemeindeleben, Ost-Berlin 1956.

3 In der Einleitung zu Rosen a. a. O., und den Fußnoten sind nur einige ganz spärliche juristische Hinweise.

4 Im "Staatslexikon“, 6. Aufl., Bd. 11, Freiburg 1970, hat Bechert unter dem Stichwort "Staatskirchen und Staatsreligionen " auch die buddhistischen Staaten behandelt (S. 307-314, mit Literaturangaben, S. 315 f.).

5 Mittlere Sammlung (Mijjhima-Nikāya) des Pālikanons, Rede Nr. 65, siehe auch Parājika I, 3. 
da manche auf Trieben beruhende Dinge im Orden offenbar werden, gibt der Meister den Jüngern die Regel an, um eben diese auf Trieben beruhenden Dinge zurückzuweisen. Nicht eher werden da manche auf Trieben beruhende Dinge im Orden offenbar, bis nicht der Orden Größe, hohe Spenden, hohen Ruhm, viel Wissen, späte Jahre erreicht hat."

So entstanden im Laufe der 45jährigen Lehrtätigkeit des Buddha, während er kreuz und quer durch Nord-Indien wanderte, immer mehr Vorschriften innerhalb des Ordens als eines „besonderen Gewaltverhältnisses“, für das der Buddha alleiniger Gesetzgeber war.

Als der Buddha starb und ein halbes Jahr später das erste Konzil des Ordens bei Rajāgaham (heute Rajgir), der Hauptstadt des Staates Magadha (heute Bihar), abgehalten wurde ${ }^{6}$, bestanden schon 227 numerierte Mönchsregeln, zu denen noch zahlreiche unnumerierte kamen. Nach der Überlieferung war es der Ordensältere Upāli, der den ganzen Vinaya aus dem Gedächtnis rezitierte und so für künftig festschrieb. Dieser Upāli erscheint in den Texten des Pālikanons immer als Spezialist für Ordnung und Zucht der Mönche ${ }^{7}$. Er war ein Landsmann des Buddha aus dem Sakyerstamme, der untersten Kaste entstammend ${ }^{8}$, und hatte beim ersten Konzil bereits 43 Ordensjahre hinter sich, d. h. er hatte die gesamte Entwicklung des Ordensrechts selber miterlebt. Nachdem er die Ordensregel (Vinaya) vorgetragen hatte, rezitierte Ananda, ein Vetter des Buddha, die Lehre (Dhamma), die in den Lehrreden (Suttā) bestand. So wird immer von dhamma-vinaya, Lehre und Zucht, Theorie und Praxis gesprochen, wenn der Inhalt des Buddhismus angegeben werden soll. Der Begriff Vinaya bedeutet etwa „Hinwegführung“, und zwar im Sinne der Hinwegführung schlechter Eigenschaften und unheilsamer Verhaltensweisen. Insofern ist Vinaya Zucht oder gar Erziehung, weil die Entwicklung eines guten Verhaltens nur möglich ist, wenn das Gegenteil überwunden wird. Während nun im Vinaya vorwiegend die zu lassenden Dinge behandelt sind, werden in der Lehre auch die zu entwickelnden Eigenschaften aufgeführt, so daß beide Teile sich ergänzen.

\subsection{Tradierung des Vinaya}

Der Vinaya wurde seit jener Zeit, also seit 2500 Jahren, als Verfassung des buddhistischen Ordens bewahrt. Die älteste schriftliche Festlegung soll im Jahre 29 v. Chr. auf Ceylon erfolgt sein, indem unter König Vattagāmani-Abhaya auf Palmblättern der gesamte Pālikanon aufgezeichnet wurde9, der seitdem „Dreikorb“ heißt, weil seine Teile drei Körbe Palmblattmanuskripte füllten. Zwischen Asoka und dem ersten nachchristlichen Jahrhundert bildeten buddhistische Schulen, die sich des Sanskrit bedienten, ebenfalls einen Kanon aus, der stets auch einen Vinaya umfaßte. Diese Formen des Vinaya in Sanskrit sind im ganzen verlorengegangen, nur wenige Bruchstücke sind in Zentralasien (Turfan und Gilgit) gefunden worden. In chinesischer Übersetzung sind jedoch in der chinesischen Sammlung der buddhistischen Texte nicht weniger als fünf Sanskrit-Versionen verfügbar ${ }^{10}$, nämlich die

6 Einzige Quelle dafür: CV XI.

7 In der Angereihten Sammlung (Anguttara-Nikāya) Einerbuch, Rede 19 (Nr. 24 in der deutschen Übersetzung v. 1969) steht er an der Spitze der Kenner der Ordenszucht.

$8 \mathrm{Vgl.} \mathrm{CV} \mathrm{VII,} 1$

9 Dipavamsa 20, 20; Mahāvamsa 33, 100.

10 Darüber ausführlich Frauwallner, a. a. O. sowie Dutt 1962, S. 78 mit Quellen der 5 Texte und S. 70 über die Sanskrit-Fragmente. 
folgender Schulen: Sarvāstivādinn"11, Mūlasarvāstivādin, Mahīšãsaka, Mãhasanghika, Dharmaguptaka. In den Formeln der numerierten Regeln stimmen diese 5 Schulen inhaltlich nahezu mit dem Pālitext überein. Nur die Reihenfolge der Regeln und ihre Entstehungsgeschichte weicht öfter ab sowie die noch zu behandelnden Zusätze. Einer dieser 5 Texte, nämlich der der Mūlasarvāstivādin, hat in tibetischer Version Eingang in den dortigen Kanon gefunden (Dulva) ${ }^{\mathbf{1 2}}$. Auch auf die 300 Mönchsgebote des chinesischen Taoismus wirkte der buddhistische Vinaya ein ${ }^{\mathbf{1 3}}$.

Von Ceylon im Süden bis zu den Burjäten in Sibirien, von Ladakh im Himalaya bis nach Japan ist der Vinaya bis heute die Grundlage der Ordensverfassung geblieben. Er ist derjenige Teil der buddhistischen Tradition, in welchem die verschiedenen Schulen des Buddhismus am meisten übereinstimmen ${ }^{13 a}$. Unter den Anpassungen an Klima und soziale Verhältnisse der anderen Länder ist am auffallendsten und gleichzeitig belanglosesten die Tatsache, daß die Mönche des südlichen oder Theravāda-Buddhismus das gelbe Gewand (orange bis ocker) beibehielten, während die Tibeter ein rotes, die Zen-Mönche Ostasiens eine schwarze Robe anlegten.

In den Ländern des Theravāda-Buddhismus wurden im Laufe der Jahrhunderte die Vorschriften des Vinaya an die örtlichen und zeitlichen Verhältnisse der Staaten, in denen der Orden als eine autonome Körperschaft bestand, angepaßt. In Cey$\operatorname{lon}^{14}$ gab es z. B. drei Formen sog. Katikāvatas (Ordensvorschriften): zuerst lokale für bestimmte einzelne Klöster (etwa erweiterten Hausordnungen vergleichbar), dann von den singhalesischen Königen vom 12.-18. Jahrhundert für den Sangha der ganzen Insel erlassene, schließlich unter britischer Herrschaft Katikāvatas der einzelnen Ordenszweige Ceylons. Die Ermächtigungsgrundlage für solche Veränderungen läßt sich aus dem Kanon selber ableiten. Der Buddha gestattete nämlich an seinem letzten Lebenstage, die "kleinen und kleinsten“ Regeln aufzuheben ${ }^{15}$. Da im Orden aber keine Einigung zu erzielen war, was darunter zu verstehen sei, verzichtete man zunächst auf jede Änderung und nahm solche erst nach vielen Jahrhunderten vor, auch dann aber nur in der Form von Zusatzregeln, die teils "Gesetzesdurchbrechungen" waren. Ob allerdings der Ausschluß niederer Kasten vom Orden und die Erweiterung von Ordensausschließungsgründen mit dem ursprünglichen Vinaya vereinbar ist, darf füglich bezweifelt werden.

\subsection{Gliederung des Vinaya}

Der Vinaya des Pālikanons - auf ihn als vollständigste und besterhaltene From des Vinaya ${ }^{16}$ wird im folgenden vorwiegend einzugehen sein - gliedert sich in drei Teile oder in fünf Bücher: Der erste Teil heißt Khandaka. Er enthält im Rah-

11 Dies ist der Vinaya, den Rosen a. a. O. behandelt: Dort S. 42-49 eine Konkordanz der Regeln der 6 Schulen.

12 Enthalten im Kandschur, Tokio-Ausgabe Bd. 41-45; Lhasa-Ausgabe Bd. 1-13, Peking-Ausgabe Bd. 1-16.

13a In China wurde von Pai-chang $(749-814)$ für die Zen-Mönche eine Klosterregel erlassen, die dann mit

13 Hackmann, Die 300 Mönchsgebote des chin. Taoismus, Amsterdam 1931.

13 Hackmann, Die 300 Mönchsgebote des chin. Taoismus, Amsterdam 1931. to the 18th century (critically edited, translated and annotated), München 1971 (Münchener Studien zur Sprachwissenschaft, Beiheft N). Über den Ausschluß niederer Kasten: S. 295; über Ordensausschluß: S. 221.

15 Längere Sammlung (Digha-Nikāya), 16 Rede, Teil VI; dazu dann CV XI, 1.

16 Die Ưberlegenheit dieses Vinaya über andere Rezensionen begründet Dutt, S. 69, 74, 173, a. A. Frauwallner, der aber keine Nachweise für eine bessere Rezension geben kann. 
men der allgemeinen Ordensgeschichte von der Erwachung des Buddha bis zum zweiten Konzil von Vesali (100 Jahre nach dem Tod des Buddha) in zwei Büchern die unnumerierten Regeln der Ordensverfassung. Das Große Buch $($ Mahāvagga $=\mathrm{MV}$ ) enthält 10, das Kleine Buch (Cullavagga = CV) 12 Kapitel. Diese 22 Kapitel lassen sich in drei Gruppen gliedern, wobei sie hier durchgezählt $\operatorname{seien}^{17}: 1$. Die fünf großen Institutionen des Ordens: Ordination als Novizen oder Mönche (I), dazu gehörig Beschränkungen während der Probezeit (XII) oder bei Suspension der Mitgliedschaftsrechte (XIII); zweitens die vierzehntägige UposathaVersammlung (II), dazu Teilnahmebedingungen daran (XIX); drittens die dreimonatige Regenzeit-Klausur (III), mit der Pavārana-Versammlung an deren Ende (IV); viertens Verwaltungsakte des Ordens hinsichtlich allgemeiner Erfordernisse (IX) sowie besonderer Arten (XI); fünftens Streitschlichtungsverfahren (XIV), dabei Regeln für die beiden gravierendsten Streitfälle der Ordensgeschichte, nämlich die von Kosambi (X) und die Devadattos (XVII).

2. Die drei Lebensnotwendigkeiten: erstens Ernährung, mit Almosengang und Vorschriften für Krankheit (VI); zweitens Wohnung und Grundbesitz des Ordens (XVI); drittens Besitz von Mobilien wie Kleidung, Stoff und Schale (VII), dabei Institutionen der Robenverteilung am Ende der Regenzeit, sog. Kathina (VIII) und Vorschriften für Schuhe und Leder (V).

3. Verschiedenes: Regeln über allgemeines Gehaben nach außen (XVIII), Regeln über diverse Kleinigkeiten (XV), spezielle Regeln für Nonnen (XX), Berichte über die beiden ersten Konzile (XXI, XXII).

In diesem ersten Teil liegt der Schwerpunkt in dem, was wir Organisationsrecht einer religiösen Korporation nennen könnten. Es werden jeweils die Anlässe erzählt, die dazu führten, daß der Buddha irgendwann eine Erlaubnis oder ein Verbot aussprach. Durch die Erzählungen der Entstehungsgeschichte der jeweiligen Norm wird die trockene Materie recht aufgelockert.

Der zweite Teil heißt Sutta-vibhanga, sein Inhalt wird auch Pātimokkha18 genannt. Im Unterschied zu den unnumerierten Regeln der Khandakas sind die des Pātimokkha numeriert. Es handelt sich hierbei um das Strafgesetzbuch des Ordens. Darin sind als erstes Buch 227 Regeln für die Mönche enthalten. Ein zweites Buch umfaßt den entsprechenden Pātimokkha für den etwas später gegründeten Nonnen-Orden, der in den Theravāda-Ländern seit $456 \mathrm{n}$. Chr. ausgestorben ist. Dieser „Bhikkuni-Pātimokkha“ enthält 130 zusätzliche Regeln für die Nonnen, die aber meist ganz allgemein-menschliche Tatbestände regeln.

Der dritte und letzte Teil heißt Parivāra. Er ist nicht viel mehr als ein Inhaltsverzeichnis und Repetitorium zum Ganzen und dürfte späterer Herkunft sein. Entsprechend der Scholastik der Theorie (Abhidhamma) kann der Parivāra als Scholastik der Praxis (Abhivinaya) bezeichnet werden ${ }^{19}$.

\footnotetext{
17 Hier folge ich Frauwallner; weiter unten wird wieder nach MV und CV getrennt zitiert.

18 Auf deutsch liegen vom Pali-Patimokkha nur die drei ersten Gruppen v. Regeln vor: Seidenstücker, Ztschr. f. Buddhismus $1924 / 5$ (Bd. 6), S. 64-77. Auf englisch, außer der allg. Ubbersetzung v. Miss Horner, Nyanamoli, Patimokkha, 227 fundamental rules of the Bhikkhu, Bangkok, 1966; vergl. auch W. Pachow, A comparative study of the Prātimoksa, Santiniketan 1955. Die Regeln des Patimokkha aus dem tibet. Dulva wurden 1915 ins Englische übersetzt. Eine Gegenüberstellung der Úbersetzungen zum Päli-Vinaya siehe bei Getsul Lobsang Jivaka, A comparative analysis of Tibetan and PaliPratimoksas, in der Londoner Zeitschrift „The Middle Way “ 1961/2, S. $168 \mathrm{f}$

Im folgenden werden die jeweiligen Regeln des Patimokkha der Nonnen durch ein vorangestelltes $\mathrm{N}$ (Nonnen) gekennzeichnet.

19 Vergl. dazu Miss Horner, Part VI, Einl. S. XXXV.
} 


\subsection{Die acht Gruppen von Taten}

Der mittlere Teil, der Pātimokkha, ist ähnlich wie unsere Strafgesetzbücher, nach der Schwere der Taten geordnet. Es sind darin 8 Gruppen aufgeführt, die in allen Textüberlieferungen in dieser Reihenfolge der Gruppen vorkommen ${ }^{20}$. Diese 8 Gruppen, die jeweils für Mönche und Nonnen vorkommen, lauten wie folgt:

1. Parājika (Pj): Ausschlußtaten. Dies sind die schwerwiegendsten Delikte, die „Kapitalverbrechen“ (4 der Mönche, 8 der Nonnen). Dabei wird, als einziger Fall, das Strafmaß im Gesetz selber erwähnt. Ein Verstoß führt hier nämlich zu lebenslänglichem Ordensausschluß. Dies ist jedoch keine Exkommunikation, da der Täter nicht aus der "Gemeinschaft der Gläubigen", sondern nur aus der Ordensgemeinschaft ausgeschlossen wird. Diese Strenge wird dadurch relativiert, daß der Betreffende nach dem Tode in einem späteren Leben wieder Ordensmitglied werden kann, weil die Überzeugung von der Fortdauer der Existenz damals selbstverständlicher Bestandteil der Religion war. Die vier Delikte der Mönche sind: Geschlechtsverkehr, Diebstahl, Menschenmord, Anmaßen übernatürlicher Fähigkeiten. Von den drei christlichen Ordensgelübden (Armut, Keuschheit, Gehorsam) sind hier nur die beiden ersten berührt. Bemerkenswert ist folgendes: Im Orden ist das erste Tugendgebot das Abstehen von Geschlechtsverkehr, während das erste Tugendgebot der buddhistischen Laien das Abstehen von Töten ist. Und in der Entwicklung der menschlichen Gesellschaft war nach buddhistischer Tradition der Diebstahl das zeitlich erste Vergehen im heutigen Sinn ${ }^{21}$.

2. Sanghādisesa (SA): das sind Taten, die zur zeitweisen Suspendierung der Rechte als Ordensangehöriger führen, entsprechend einer zeitweiligen Aberkennung der bürgerlichen Ehrenrechte. Die 13 Verfehlungen dieser Gruppe (bei Nonnen 10) machen eine Gemeindeverhandlung notwendig. Wer sein Vergehen sofort gestand, wurde 6 (Nonnen 14) Tage suspendiert; bei Verheimlichung kamen zusätzlich die Tage des Verschweigens hinzu. Der Täter hatte während dieser Zeit nur noch Pflichten, aber keine Rechte. Bei den vier letzten Taten war außerdem dreimalige vorherige Abmahnung vor der Verurteilung notwendig. Das nähere Verfahren bis zur endgültigen Rehabilitation ist in CV II-III geregelt. Die in Pj und SA genannten Taten werden zusammenfassend als schwerste Verstöße (dutthulla) bezeichnet.

3. Aniyata (Ani): Hier sind nur 2 Tatbestände des Umgangs mit Frauen aufgeführt, bei denen eine bloße Beweisvermutung aufgestellt wird, ob es sich um $\mathrm{Pj}, \mathrm{SA}$ oder nur $\mathrm{P}$ handelt.

4. Nissaggiya (Ni): Diese und die beiden folgenden Gruppen betreffen Taten, die nur zur Beichte verpflichten, ohne daß eine weitere Strafe verhängt wird. Das Besondere der 30 (bei Nonnen 12) Taten der Gruppe Ni besteht darin, daß außer dem Bekenntnis (Beichte) als Nebenfolge eine Rückgabe des Gegenstandes, auf den sich die Tat bezog, erforderlich ist, und zwar an die Ordensgemeinschaft. Hier geht es also um Besitz, der für einen Mönch zu kostbar oder zuviel ist oder der durch verbotene Handlungen erlangt worden war. Der Besitz muß dann abgeliefert werden, d. h., er wird beschlagnahmt und eingezogen. Er kann allerdings dem Täter nach der Beichte auch zurückgegeben werden, ausgenommen, wenn es sich um Geld handelt (Ni 18) ${ }^{22}$. Sachlich geht es bei den 30 Taten vor allem um Kleidung, Stoff,

20 Vergl. näher Frauwallner a. a. O. und Rosen, a. a. O., S. $42 \mathrm{ff}$.

21 Längere Sammlung 26. Rede.

22 Vergl. Horner, Vinaya Part II, Einl. S. XII. 
Matten, Schalen. Besondere Bedeutung hat Ni 23, wonach Arznei- und Heilmittel nicht länger als eine Woche aufbewahrt werden dürfen. Im Dulva sind hiervon 4 Regeln leicht verändert und eine durch einen ganz anderen Tatbestand ersetzt ${ }^{23}$.

5. Pācittiya (P): Diese größte aller acht Gruppen (92 Regeln für Mönche, 96 für Nonnen) erfordert eine einfache Beichte. Inhaltlich sind hier alle Arten von Rechtsgütern betroffen. Eine nähere Behandlung würde den Rahmen der vorliegenden Arbeit sprengen. Im Dulva sind 16 Regeln verändert ${ }^{23}$.

6. Pātidesaniya (Pd): Hier wird bei 4 ( 8 bei Nonnen) Taten eine qualifizierte Beichte gefordert, ein Reuebekenntnis, das stets vor versammelter Gemeinde abzugeben ist, während sonst auch vor einer Einzelperson gebeichtet werden kann. Bei allen vier Vergehen geht es hier um Essen.

7. Sekhiya (Se): Dies sind bloß Ordnungswidrigkeiten, Disziplinarverstöße, Verletzungen des Anstands, "mere breaches of etiquette" ${ }^{24}$. Die 75 Regeln dieser Art (im Dulva sind es 105, bei den Sarvāstivādin sogar 113) gelten als ein Gebiet, das sozusagen im Vorfeld des Strafrechts steht und bei dem nur eine Verletzung der asketischen Konvention vorliegt. Daher ist hier keine Beichte nötig, überhaupt wird keine äußere Sanktion, nicht einmal Abmahnung, gefordert. Der Täter soll sich diese Regel lediglich selber im Gewissen vorhalten, wenn vierzehntägig die 227 Regeln rezitiert werden, um an ihre Einhaltung zu erinnern. Ein Gleiches gilt übrigens auch von den unnumerierten Regeln, den Khandakas, sofern diese als du-kata (leichtes Vergehen) qualifiziert sind.

8. Adhikarana (Ak): Die letzten 7 Regeln betreffen weder Strafrecht noch Anstandsregeln, sondern befassen sich mit Prozeßrecht: sie enthalten Verfahrensvorschriften zur Streiterledigung in der Gemeinde. Im letzten Teil dieser Arbeit wird näher darauf einzugehen sein.

\subsection{Ordnung der Tatbestände des Pātimokkha}

Innerhalb der acht Gruppen - besonders bei den umfangreicheren - findet sich nun nicht, wie wir es von unserem Strafgesetzbuch gewohnt sind ${ }^{25}$, eine sachliche Ordnung nach Rechtsgütern, sondern die Regeln sind der Niederschlag eines allmählich historisch gewachsenen Fallrechts (case law). Es hat den Anschein, daß die einzige Ordnung eine chronologische war ${ }^{26}$. Jede neu erlassene Regel einer Gruppe wurde an die bisher genannten angehängt, und so wurde der Pātimokkha bis zum Tode des Buddha allmählich auf die oben genannte Zahl erweitert. Diese rein chronologische Ordnung macht das Ganze naturgemäß weniger übersichtlich. Die Abweichungen der anderen Schulen hinsichtlich der Reihenfolge sind wahrscheinlich spätere Versuche zu einer sachlicheren Ordnung, die allerdings bei ihnen noch weniger geglückt ist ${ }^{27}$.

Wenn die Redaktoren der Pāli-Ưberlieferung keine Änderung der Reihenfolge zugunsten einer sachlicheren Ordnung vorgenommen haben, so liegt das wohl an der Scheu, eine Tradition zu ändern. Aber es dürfte noch ein weiterer Grund hinzu-

23 Vergl. Jivaka a. a. O.

24 Dutt, 1962, S. 69

25 Dutt a. a. O. weist auch auf die Ordensregel des hl. Benedikt hin.

26 Horner, Part 1, Einl. S. XV meint zwar auch, daß die Regeln allmählich nach Bedarf erlassen wurden, bezweifelt aber eine chronologische Reihenfolge. Für die vier Pj-Taten wird in CV XI aber ausdrücklich eine chronologische Reihenfolge angegeben.

27 Besonders chaotisch der Vinaya des Mahāsanghikas. 
kommen. Die 227 Regeln wurden alle 14 Tage von den Mönchen gemeinsam rezitiert, um sie immer wieder im Gedächtnis aufzufrischen. Wenn nun dabei z. B. alle Regeln über den Besitz nacheinander vorgetragen würden, so würde das die Aufmerksamkeit sehr ermüden, und man würde kaum auf die kleinen Unterschiede achten. Wenn dagegen beispielsweise 40 Regeln über den Besitz bunt vermischt auf die 8 Gruppen und innerhalb ihrer verteilt sind, dann wird dadurch eine größere Aufmerksamkeit erzwungen. Der Mönch, der den Vortrag der Regeln anhört, soll ja bei jeder sein Gewissen erforschen, ob er in den letzten 14 Tagen dagegen verstoßen hat. Die systemlose Reihenfolge zwingt ihn nun dazu, stets hellwach zu sein, weil der Geist eine chaotische Reihenfolge schwer behalten kann und daher projizierende Abwehrmaßnahmen des Unbewußten schwerer möglich sind. Was für den an systematische Ordnung gewohnten Juristen ein Mangel ist, das kann also psychologisch ein Vorteil sein.

Der gesamte Inhalt der 227 numerierten und der zahllosen unnumerierten Regeln ist letztlich nichts anderes als eine weitgespannte Auffächerung der 8 buddhistischen Grundtugenden, die als solche in den Lehrreden behandelt sind 28 . Sie betreffen vier große Gebiete des Redens (Verstöße gegen: Wahrheit, Eintracht, Höflichkeit und Nutzen; d. h. Lüge, Hintertragen, Beleidigen, Schwatzen) und vier große Gebiete des Handelns (Verstöße gegen: Leben, Eigentum, geschlechtliche Reinheit und Lebensführung im ganzen; d. h. Töten, Stehlen, Ausschweifen, falscher Wandel). Diese 8 Grundtugenden gelten grundsätzlich auch für den Laien. Im Vinaya werden sie nur spezialisiert für die Ordenssituation, wobei das Schwergewicht beim rechten Wandel liegt ${ }^{29}$, weil sich darin der Mönch am meisten vom Laien unterscheidet. Im übrigen enthalten die Regeln des Vinaya vieles, was für das Zusammenleben der Menschen überhaupt von Bedeutung ist, ganz unabhängig von der Ordenssituation.

\subsection{Aufbau der einzelnen Regel}

Die Überlieferung der 227 Regeln folgt einem einheitlichen System, das grundsätzlich folgende Stufen aufweist:

1. Am Anfang steht die Vorgeschichte, d.h. der casus legis. Da wird berichtet, wie ein Ordensangehöriger dazu kam, eine bestimmte Tat zu begehen. Diese Vorgeschichten sind oft sehr ausführlich und liefern ein lebendiges Bild der damaligen kulturellen Situation. Die späteren Schulen weichen in den Vorgeschichten vom Pālitext und untereinander manchmal ab.

2. Auf die begangene Tat folgte die Reaktion der öffentlichen Meinung, indem Ordensangehörige oder buddhistische Laien oder auch Anhänger anderer Weltanschauungen an der Tat Anstoß nahmen, weil sie nach ihrem Rechtsempfinden dem höheren religiösen Leben widersprach. Das öffentliche Gewissen als Kontrollinstanz auf naturrechtlicher ${ }^{30}$ Basis erscheint also als sehr wach. Nur in ganz wenigen Fällen griff der Buddha von sich aus eine Tat auf.

3. Der Protest der öffentlichen Meinung wird dann dem Buddha als dem Gesetzgeber des Ordens, der „obersten Kircheninstanz“, berichtet mit dem Ansinnen,

28 Dazu näher, Hecker, Die Ethik des Buddha, 2. Aufl., Hamburg 1976.

29 Mindestens 102 der 227 Regeln lassen sich zum rechten Wandel zählen.

30 Vergl. Hecker, Der Beitrag des Buddhismus zur Frage des Naturrechts, in: VRU 1970, S. 349-355. 
das Verhalten abzustellen. Das ähnelt eher einer Petition als einer Gesetzesmotion, weil kein formulierter Antrag vorkommt.

4. Der Buddha lädt daraufhin die jeweilige regionale Gemeinde der Ordensangehörigen zu einer Versammlung ein, vor der der Täter befragt wird. In allen berichteten Fällen gesteht der Täter sofort. Nach dem Geständnis tadelt der Buddha den Täter. Er wirft ihm vor, daß er durch jene Tat in mehrfacher Weise gegen den allgemeinen Geist der Gemeinschaft verstoßen habe, d. h. gegen das Naturrecht ${ }^{30}$. Er sagt ihm, daß seine Tat verstoße gegen: die materielle Bedürfnislosigkeit („leicht $z u$ unterhalten und $z u$ versorgen"), soziale Anspruchslosigkeit (Bescheidenheit), seelische Genügsamkeit (Ledigung, Zucht), zuversichtliche Zufriedenheit, Abschichten von Eigensucht und Einsatz von Tatkraft ${ }^{31}$.

5. Dann erst erläßt er das Gesetz, indem er für künftig eine neue, für alle Ordensmitglieder verbindliche Regel festlegt. Dabei gibt er 5 Paare allgemeiner Gründe an, warum er wieder eine Regel erlasse: für die Wohlfahrt der Gemeinschaft und für ihr Wohlbefinden; für die Zurückweisung zweifelhafter Subjekte und das Wohl der gutgesinnten Mönche; für die Abwehr gegenwärtiger Triebe und auch künftiger; für die Zuversicht Nichtzuversichtlicher und das Wachstum der Zuversichtlichen; für die Fortdauer des guten Gesetzes und zum Schutze der Ordenszucht.

6. In manchen Fällen, vor allem bei den schweren Vergehen, folgt nun eine Geschichte der Gesetzesänderungen. Es wird berichtet, aus welchen Anlässen eine Verschärfung oder eine Abmilderung der Regel zweckmäßig erschien. In einem Extremfall, in P 32 (Essen zu mehreren), wurde die Regel nicht weniger als siebenmal geändert. Gelegentlich nehmen die Mönche eine Abänderung vorweg, indem sie darauf vertrauen, der Buddha werde in diesem Fall schon eine vernünftige Einschränkung vornehmen ( $\mathrm{Ni}$ 6: Roben erbitten).

7. Aus offenbar späterer Zeit folgt nun ein Kommentar, der die einzelnen Begriffe der Norm definiert und Erläuterungen zum Verständnis der Tragweite gibt. Manchmal werden auch die Begriffe der Definition noch wieder definiert (Subkommentar). Auch generelle Strafausschließungsgründe werden aufgeführt, die unten näher zu erörtern sind.

8. Den Schluß bildet in vielen Fällen, besonders bei den ersten Gruppen, eine Fallsammlung (Kasuistik). Da wird berichtet, wie Mönche etwas erleben und nun zweifeln, ob ein Regelverstoß vorliegt. Sie befragen deswegen den Buddha (oder, seltener, einen kompetenten Ordensbruder wie insb. Upāli), und dann wird entschieden, ob das Vergehen vorliegt oder ein anderes oder gar keins.

\section{Strafausschließungsgründe}

An vier Stellen finden sich im Vinaya Strafausschließungsgründe:

1. Selten werden sie im Text der Regel des Pātimokkha selber schon mitgenannt.

2. Alle Regeln des Pātimokkha der Mönche und der Nonnen, die Verstöße behandeln (also ausgenommen nur die Prozeßregeln Ani und Ak), enthalten am Ende des Kommentars eine Aufzählung, wann kein Vergehen (an-āpatti) vorliegt. Dabei stehen Mängel im objektiven und subjektiven Tatbestand, Rechtfertigungs-

$31 \mathrm{Pj}$ I, 5; andere Ưbersetzung der 5 Paare: Rosen, S. 14 oder Anguttara-Nikāya II/70 und X/31. 
und Entschuldigungsgründe und besondere persönliche Strafausschließungsgründe ungesondert nebeneinander. Diese Aufzählung des Kommentars hat mehr soziologischen als formaljuristischen Charakter, indem Hinweise gegeben werden sollten, wann kein Vergehen vorliegt, aus welchem Grunde auch immer. Daß z. B. bei „Mangel im Tatbestand“ keine Strafbarkeit gegeben ist, scheint eine Selbstverständlichkeit, dürfte aber zur Schulung der Subsumtionsfähigkeit oft hervorgehoben werden. Es handelt sich dann um eine Art Anweisung zu genauer Beachtung der Begriffe. Wenn z. B. „Nonne“ gesagt wird, dann hebt die Anāpatti-Klausel hervor, daß darunter keine Novizin zu verstehen sei. Wenn "fremde Sache“ gesagt wird, dann wird betont, daß keine herrenlose gemeint sei usw. Außerdem läßt sich sagen, daß die Erwähnung solcher Begriffe ein spezielles Analogie-Verbot beinhaltet, da nach der Generalklausel in MV VI, 40 analoge Anwendungen im Vinaya nicht grundsätzlich verboten sind.

3. Bei den zur Entscheidung gelangten Fällen der Kasuistik des Pātimokkha werden Strafausschließungsgründe genannt, die den Fall dann zu einem Nichtvergehen oder einem anderen Vergehen machen.

4. In den Khandakas werden bei der Schilderung von Fällen, die zur Strafbarkeit wegen eines leichten Vergehens (dukata) führen, die Strafausschließungsgründe in der Schilderung mit erwähnt.

Im folgenden wird mit den beiden Gründen begonnen, die bei sämtlichen Anāpatti-Klauseln, und zwar als erste, vorkommen. Andere Strafausschließungsgründe folgen dann.

\subsection{Nullum crimen sine lege}

Bei allen 218 Mönchsregeln findet sich die Anāpatti-Klausel, daß für den Ersttäter kein Verstoß vorliege. Damit ist schon damals der Rechtsgrundsatz nullum crimen sine lege, nulla poena sine lege (kein Verbrechen und keine Strafe ohne Gesetz) ausdrücklich eingeführt worden. Der Grund, daß der Täter abgeschreckt worden wäre, hätte er die Strafbarkeit und die Strafe gekannt, trifft besonders bei den 4 Taten der Pj-Gruppe zu, denn die Ersttaten waren dort so gelagert, daß es Grenzfälle waren, bei denen das Bewußtsein der Rechtswidrigkeit auf Grund einer allgemeinen Gewissensstimme nicht so deutlich zu sein pflegt. Wäre es den Tätern hier vor Augen gewesen, daß ihre Tat zum Ordensausschluß führen würde, dann hätten sie sie sicher unterlassen. Der spezial- und generalpräventive Charakter des obigen Rechtsgrundsatzes erfährt hier in der Rechtsgeschichte eine seiner frühesten Bestätigungen $^{32}$.

Auffällig ist, daß dieser Rechtsgrundsatz im Vinaya der Sarvāstivādin fehlt ${ }^{\mathbf{3 3}}$. Das könnte ein Indiz für die sehr viel spätere Abfassung dieses Vinaya sein, als die Jahrhunderte zurückliegende Ersttat keine Erwähnung mehr zu verdienen schien und bei den Redaktoren jener Sekte ein Gefühl für den Wert und Sinn jenes Rechtsgrundsatzes nicht mehr vorhanden war.

32 Horner, Part I, S. XV.

33 Siehe Rosen, S. 19. 


\subsection{Unzurechnungsfähigkeit}

Ebenfalls bei allen materiall-rechtlichen Tatbeständen der Regeln für Mönche und Nonnen findet sich der Grundsatz, daß Geisteskrankheit (ummado) die Schuld ausschließt. Die englische Übersetzung gibt dies meist richtig mit „mad“ wieder, nur bei drei Regeln steht statt dessen „out of his mind“ (Pj III, SA VI, IX), obwohl im Pāli auch hier ummado steht. In je einem Fall bei Mönchen (Ni 19) und Nonnen (NP 18) sind Ersttat und Geisteskrankheit die einzigen Gründe für „anāpatti“.

Nicht so einfach zu verstehen ist dagegen ein weiterer Strafausschließungsgrund, der, wo er vorkommt, stets nach der Geisteskrankheit aufgeführt wird. Er kommt aber nur in folgenden Tatbeständen vor: bei drei der vier Pj-Vergehen, nämlich außer bei Tötung; bei 4 der 13 SA-Tatbestände (2 Keuschheitsfälle, 2 Ordensspaltungen) sowie bei der letzten Se-Regel (Se 75); ferner bei zwei Pj-Vergehen der Nonnen (NPj I, IV). Der Begriff lautet im Pāli khitta-citta (etwa „umgeworfene Psyche“) und wird im Englischen mit „unhinged“ (Pj I, SA I-II, Se 75), „his mind is unhinged“ (Pj II, NPj I u. IV), "out of his mind" (SA X-XI), „unbalanced“ (Pj IV) übersetzt. Die schwankende Übersetzung läßt vermuten, daß die Sache unklar war, zumal "out of mind" auch für die Geisteskrankheit als Übersetzung benutzt wurde. Die Tatsache, daß dieser Strafausschließungsgrund nur bei acht Regeln der Mönche und zwei der Nonnen vorkommt, läßt darauf schließen, daß es sich um ein Phänomen handelt, das nicht wie die Geisteskrankheit stets den Willen ausschließt. Es könnte sich um vorübergehende Gemütsverwirrung, Bewußtseinstrübung, wie durch Bestürzung, Furcht oder Schrecken, und deshalb verminderte Zurechnungsfähigkeit handeln, wenngleich offen bleibt, warum das nicht bei allen Delikten die Schuld ausschließen sollte. Bei uns würde dadurch überhaupt nur der Notwehrexzeß straffrei, nicht aber andere Delikte. An anderen Stellen (MV II, 22; IX, 4; CV III, 27; Pj I, 8) machen Geisteskrankheit und diese Gemütsverwirrung auch zivilprozeßrechtliche Akte unwirksam.

In allen 14 genannten Fällen (8 der Mönche, 2 der Nonnen, 4 an anderen Stellen) steht nach jener "Gemütsverwirrung" noch ein Begriff vedan'atta, der mit "Leidensdruck“ wiedergegeben werden könnte (engl. "afflicted by pain“ oder „afflicted with pain“). Wenn nicht in CV III, 27 Geisteskrankheit und Gemütsverwirrung ausdrücklich gesondert von diesem "Leidensdruck" abgehoben und alle drei als getrennte Phänomene behandelt würden, wäre man versucht zu sagen, daß der Leidensdruck nur eine nähere Bestimmung der Gemütsverwirrung wäre, eben drückendes Leiden. So bleibt offen, was die genaue, juristisch relevante Bedeutung ist. Nicht gemeint sein kann etwa Ausschließung der Zurechnungsfähigkeit durch Folterdruck, denn das müßte für alle Delikte gleichermaßen gelten und paßt auch nicht für zivilrechtliche Akte. Näher liegt es, daran zu denken, daß einer aus Schmerz „von Sinnen“ ist. Vielleicht läßt sich eine Abgrenzung der drei Gründe für Unzurechnungsfähigkeit so treffen, daß sie sich auf die Dreiheit von Geist, Seele, Körper beziehen: Geisteskrankheit schließt stets die Zurechnungsfähigkeit aus; Gemütsverwirrung (Seele) und Leidensdruck (Körper) als mehr momentane Beeinträchtigungen werden nur bei gewissen Delikten als Gründe für den Ausschluß der Zurechnungsfähigkeit anerkannt. 


\subsection{Mängel des subjektiven Tatbestandes}

Als Grundprinzip kann hervorgehoben werden, daß der Pātimokkha vorwiegend Gesinnungsstrafrecht ist. Bestraft wird der böse Wille, entscheidend ist also die subjektive Komponente, das Motiv. So taucht immer wieder die Frage des Buddha an einen Beschuldigten auf, wie sein seelischer Haushalt bei der Tat gewesen sei, gekleidet in die kurze Formel: „Wie war dein Herz (Kim citta)?“ Einem allgemein anerkannten Rechtsgrundsatz entspricht es dabei, daß ein Handeln unter vis compulsiva und ohne jegliche Zustimmung (a-sādiyati) die Schuld ausschließt. Bei den Strafausschließungsgründen wird dies nur selten genannt ( $\mathrm{Pj}$ I, SA II, NPj I u. IV), in allen vier Fällen bei Zwang zur Unkeuschheit.

Mangelnder Tatwille im allgemeinen (CV IV, 14) wird mit drei speziellen Begriffen umschrieben: ohne Absicht, ohne darauf zu achten, ohne es zu kennen (a-sañcicca, a-sati, a-jānata), und zwar bei folgenden Vergehen als Strafausschließungsgrund: SA II, P 10-11, 20, 61, Se 1-75, NPj I u. IV. Manchmal werden auch nur die beiden letzten Begriffe genannt (Pj III, NP 96), manchmal auch nur der letzte (Pj I), der gelegentlich auch schon als Tatbestandsmerkmal selber aufgeführt wird (P 62-64, 66). Diese drei Begriffe bedeuten: Fehlende Absicht ist mangelnder Vorsatz, worüber im nächsten Absatz Näheres zu sagen ist. Fehlendes Achten ist Fahrlässigkeit, Unachtsamkeit, Versehen. Für mangelnde Kenntnis gibt Pj III, Fall 6 folgendes Beispiel: jemand empfing vergiftete Speise und ließ andere davon kosten, die daran starben. Auf die Frage, was er sich bei dem Abgeben gedacht habe, erwiderte er, er habe von der Vergiftung nichts gewußt. Ein anderer Täter vermutete, daß das Essen vergiftet sei und wollte es durch Probieren anderer testen: er hatte dann zwar nicht den Tötungsvorsatz (keine Absicht), war aber vom dolus eventualis nicht freizusprechen. - Besonders bei den Vorschriften, die lediglich gutes Benehmen betrafen (Se), sind diese Schuldausschließungsgründe naheliegend.

Mangelnder Unrechtsvorsatz im speziellen wird als besonderer Strafausschließungsgrund genannt:

Wer eine Sache wegnimmt, um sie zu verwahren oder bloß zeitweilig zu benutzen (furtum usus), hat keinen Diebstahlsvorsatz (Pj II).

Fahrlässigkeit oder völlig unvorhersehbare Folgen schließen den Tötungsvorsatz aus (Pj III, P 61).

Wer nicht bewußt auf übernatürliche Fähigkeiten, die er nicht besitzt, anspielen wollte, besaß keinen Täuschungsvorsatz (Pj IV). Auch wer nur im Scherz etwas Unwahres sagte, log nicht (P 1). Und wer etwas weitererzählte, ohne sich liebkind machen zu wollen oder ohne Entzweiungsabsicht, verstieß nicht gegen das Verbot des Hintertragens (P 3). Dagegen liegt im Verstecken von Sachen auch bei bloßem Scherz ein Vergehen vor, wie der Tatbestand ausdrücklich hervorhebt ( $P$ 60). In $\mathrm{P} 17$ ist strafbar, wer aus Ärger jemand hinausweist, dagegen straffrei, wenn man ohne Ärger Streitmacher hinausweist (entsprechend P 74-75). Wenn anzügliche Worte oder Scheltworte lediglich zu Lehrzwecken erwähnt werden, schließt das einen Unrechtsvorsatz aus (SA III, P 2). Ebenso ist es kein Hintertragen über Vergehen anderer, wenn man nur von einem Beispiel und nicht von einem tatsächlichen Vergehen von jemand spricht (P 9). Einmal heißt es auch, daß, wer keine Verwirrungsabsicht (mohetu-kāma) hatte, von einem entsprechenden Vergehen frei sei (P 73). 
Als besonderer Entschuldigungsgrund wird gelegentlich ein Handeln aus Mitleid angeführt: Ein Mönch befreite ein Schwein, ein Reh, einen Fisch aus Fallen und entzog sie so dem Fallensteller. Weil bei ihm Barmherzigkeit vorlag, wurde kein Diebstahl angenommen ( $\mathrm{Pj}$ II, Fall 27). Dagegen ist Mitleid kein Befreiungsgrund bei Tötungen: Aus Mitleid mit einem Schwerkranken pries ein Mönch derart die Befreiung durch den Tod, daß der andere starb - der Mönch wurde wegen Tötung aus dem Orden ausgeschlossen ( $\mathrm{Pj}$ III, Fall 1). Oder beim Hinrichtungsplatz sagt ein vorbeigehender Mönch dem Scharfrichter, er möchte den Delinquenten nicht lange quälen, sondern mit einem Schlag schnell befreien: auch da wurde der Mönch wegen Tötung aus dem Orden ausgeschlossen ( $\mathrm{Pj}$ III, Fall 32).

In vielen Fällen wird Irrtum als Strafausschließungsgrund genannt. Beim Wegnehmen glaubt einer, daß der Eigner, sein Freund, natürlich damit einverstanden sei; oder einer glaubt, eine Sache sei herrenlos oder sei Beute eines Tieres oder gehöre einem Gespenst; oder er glaubt, eine fremde Sache sei die eigene. Oder: einer ergreift beim Baden versehentlich eine andere Robe; einer ißt die Portion eines anderen, in der Meinung, es sei seine; einer findet von Dieben auf der Flucht weggeworfene Früchte, die er für herrenlos hält und ißt sie (alles Pj-II-Fälle). Wer dagegen Fremdes stehlen will und nur irrtümlich Eignes ergreift, begeht eine Übertretung (du-kata) (So Pj II, Fall 4). - Beim Vorgeben höherer Fähigkeit glaubt einer aus Selbstüberschätzung daran: da liegt kein Verstoß vor ( $\mathrm{Pj}$ IV). Wer glaubt, daß ein Mönch ein Ausschlußvergehen begangen hat, obwohl es nicht der Fall ist, und es ihm vorhält, begeht keinen Verstoß gegen SA VIII (entsprechend SA IX, P 76). Wer einen nicht Volljährigen für volljährig hält, begeht kein Verstoß gegen das Gebot, Minder jährige nicht zu ordinieren (P 65).

\subsection{Rücktritt vom Versuch}

Fahrlässigkeit und Versuch gelten als mildere Tatformen, Anstif́tung und Mittäterschaft als volle Tatformen. Wenn der Täter freiwillig den Versuch abbricht und also von der Tat zurücktritt bzw. tätige Reue übt, dann ist er nach dem Vinaya, ebenso wie nach deutschem Strafrecht, straffrei. Dagegen heißt es im Vinaya der Sarvāstivādin ${ }^{34}$, daß in diesem Falle ein mittelschwerer Grad von Vergehen vorliege (thullacaya), was ungerecht ist. Auch dies zeigt, wie die anderen Rezensionen des Vinaya hinter der Pāliüberlieferung zurückstehen. Ein Beispiel: A stiftet B an, $C$ umzubringen. A bereut es, äußert aber nichts davon. Nun bringt $B$ den $C$ um. $A$ und $B$ sind Mörder. - Im gleichen Fall bereut $A$ es und bittet $B$, es nicht zu tun. $B$ aber bringt trotzdem $C$ um. $D a$ ist $A$, wie im deutschen Recht, wegen tätiger Reue straffrei, während B Mörder ist. Wenn aber auch B zurücktritt, ist keiner strafbar (Pj III, 4). Entsprechendes gilt bei Anstiftung und Rücktritt hinsichtlich Diebstahls (Pj II, 5).

34 Siehe Rosen, S. 17 und 56. 


\subsection{Befreiung wegen Erlaubnis}

Erlaubnis kann in zwei Fällen die Rechtswidrigkeit ausschließen, nämlich wenn sie von der Obrigkeit ausgeht oder wenn sie vom Betroffenen ausgeht:

In einigen Fällen ist Rechtfertigungsgrund für ein bestimmtes sonst verbotenes Verhalten, daß eine Vereinbarung des örtlichen Ordens vorlag. Die lokale Ordensversammlung brauchte dabei nicht erst den Buddha zu fragen, denn dieser hatte die Dispensbefugnis delegiert. In drei Fällen, im Pātimokkha der Nonnen, wird in der Regel selber gesagt, daß eine Ordensvereinbarung die Strafbarkeit ausschließe (NP 67, 73, 75). In anderen Fällen wird dies unter den An-āpatti-Gründen gesondert aufgeführt (P 9, 21, Ni 2, 14, 29). Auch im Mahāvagga kommt dergleichen vor: Wenn der Orden übereinkommt, jemand als geisteskrank zu betrachten, dann ist eine Versammlung auch ohne ihn vollzählig (M II, 25). Wenn der Orden übereinkommt, die Uposatha-Feier auf einen anderen als die Mondtage zu verlegen, dann ist das nur gültig, wenn es einstimmig beschlossen wurde (MV II, 36). Ungültig ist eine Vereinbarung des Ordens, daß während der Regenzeit ein Aufnahmestopp für Ordinationen erfolgen soll (MV III, 13).

Eine Erlaubnis seitens des Betroffenen, die die Strafbarkeit ausschließt (volenti non fit iniuria), gibt es nur bei Inbesitznahme von Dingen (z. B. NP 9), sie hat keinen Platz bei Keuschheitsverstößen und ist irrelevant beim Rechtsgut des Lebens. Dazu folgender Fall: Als Mönche aus Überdruß am Körper einander baten, dem anderen das Leben zu nehmen, war dies der Anlaß, daß der Buddha die Regel gegen das Töten erließ ( $\mathrm{Pj}$ III).

\subsection{Verwandtschaft}

Die Tatsache der Blutsverwandtschaft ist bei uns manchmal ein Grund, der die Strafe begründet („Blutschande“) oder sie vom Antrag abhängig macht (Familiendiebstahl im Hause) oder einen Aussagenotstand begründet (Zeugnisverweigerungsrecht). Im Vinaya kommen hauptsächlich Strafausschließungsgründe vor, und zwar besonders hinsichtlich der Erlaubnis, Gebrauchsgegenstände, die der Ordensangehörige sonst nicht haben soll, von Verwandten anzunehmen. Dabei reicht die Verwandtschaft bis in die 7. Generation rückwärts; die frühere Ehefrau eines Mönches gilt nicht als Verwandte (Ni 4). Die Fälle sind: Ni 4-9, 17, 26, P 25, 26, NNi 11-12, NP 28 (Stoff, Robe); Ni 22 (Schale); P 39, Pd 1, Se 29, 34, 37 (Essen), P 34 (Einladungen), P 47 (Medizin), NPd 1-8 (Genußmittel). Eine bevorzugte Rolle spielen dabei die Eltern: An seine Eltern darf der Mönch etwas geben (MV VIII, 22). Zu seinen kranken Eltern darf er in der Regenzeit selbst ungebeten gehen, zu anderen Verwandten dann nur gebeten (MV III, 7). Bei der Regel, die dem Mönch körperliche Berührung mit Frauen verbietet, wird gesagt, daß das Streicheln von Mutter, Tochter und Schwester nur ein leichtes Vergehen, dukata, ist (SA II, Fall 1). 


\subsection{Parapsychologisches}

Bei einer derart auf spirituelle Erfahrungen und Experimente ausgerichteten Kultur, wie es die indische war, ist es nicht verwunderlich, daß die Parapsychologie auch im Ordensrecht vorkommt. Der parapsychologische Bereich wird weder als völlig irrelevant angesehen (wie bei uns der abergläubische Versuch ${ }^{35}$ ) noch als genereller Strafausschließungsgrund gewertet, sondern es wird differenziert, und zwar bei jedem der drei Hauptdelikte unterschiedlich:

Diebe hatten zwei Kinder entführt. Ein wegen magischer Macht berühmter Mönch benutzte seine höheren Fähigkeiten nun, um die Kinder den Kidnappern abzunehmen und sie den Eltern wieder zurückzubringen. Man machte ihm den Vorwurf "Nichtgegebenes genommen zu haben" (Diebstahl). Der Buddha sprach ihn indes frei und erklärte, im Bereich der Magie läge keine solche Übertretung vor (Pj II, Fall 47).

Ein Mönch, der Exorzist war, beraubte bei einer Dämonenaustreibung einen Geist des Lebens. Der Buddha erklärte, es läge kein Ausschlußvergehen (Mord) vor, wohl aber eine mittelschwere Tatform (thullacaya). Als jemand einen anderen an einen von Geistern besetzten Ort schickte, mit der Absicht, diese möchten ihn umbringen - was auch geschah - erklärte der Buddha, daß trotz des Tötungsvorsatzes ebenfalls nur thullacaya vorläge ( $\mathrm{Pj}$ III, Fälle 24-25).

Dagegen wird Geschlechtsverkehr mit weiblichen Geistern höherer oder niederer Art ausdrücklich als Tatbestand bezeichnet, der zum Ordensausschluß führt ( $\mathrm{Pj}$ I, Fall 14), während Berührung eines weiblichen Geistes nur als thullacaya gilt (SA II, Fall 3).

In diesem Zusammenhang mag noch erwähnt werden, daß, wenn bei einer Ordensversammlung einer der Teilnehmer sich in Levitation erhebt, der Orden als nicht vollzählig versammelt gilt und die Akte deswegen ungültig sind (MV IX, 4). Der Grund dürfte darin liegen, daß bei Ordensverhandlungen keine Beeinflussung durch magische Praktiken erfolgen soll.

\subsection{Krankheit und Unfall}

Krankheit ist in sehr vielen Fällen als ein Rechtfertigungsgrund genannt, indem dem Kranken an Bequemlichkeiten erlaubt ist, was sonst den gesunden Ordensangehörigen nicht gestattet ist. Während bei den beiden schwerwiegendsten Vergehensarten ( $\mathrm{Pj}$ und $\mathrm{SA}$ ) Krankheit nie als Rechtfertigungsgrund in Frage kommt, wird sie bei den Delikten P achtmal, bei Pd zweimal und bei Se sogar bei 72 von 75 Fällen genannt. Die Fälle sind: Ein Kranker darf bei einem Verhör schweigen ( $P$ 12) oder die Versammlung verlassen ( $P$ 80), darf sich einen Schlafplatz reservieren (P 16), ein Feuer machen ( $P$ 56), mehr als drei Nächte beim Militär bleiben ( $P$ 49), und er darf es sich beim Essen erleichtern (P 31, 32, 39, Pd 3-4). Bei den Nonnen ist die Zahl der Ausnahmen für Kranke ungleich größer (NP 2-5, 7, 1517, 23-24, 34, 40, 44, 47-48, 51, 57-59, 68-70, 77-78, 84-94, 96; Pd 1-8). Die Se-Regeln sind für Mönche und Nonnen auch hinsichtlich der Regel für Kranke gleich. Bei beiden ist Krankheit stets eine Dispensation, außer in drei Fäl- 
len: die Schale über den Rand voll füllen (Se 30), Curry verstecken, um mehr zu bekommen (Se 36), gierig auf die Schalen anderer sehen (Se 38). - Außerdem ist Krankheit auch in den Khandakas häufig als Dispens genannt: Der Kranke braucht nicht den Nonnen Belehrung zu geben (CV X, 9), braucht nicht an der Wechselbefragung teilzunehmen (MV IV, 17), darf Spazierstock und Sonnenschirm auch außerhalb des Klosters benutzen ( $\mathrm{CV} \mathrm{V,} \mathrm{23-24),} \mathrm{darf} \mathrm{einen} \mathrm{Wagen} \mathrm{benutzen} \mathrm{so-}$ wie Kissen (MV V, 10; CV X, 21 für Nonnen), darf ohne seinen Mantel ausgehen (MV VIII, 23) und Knoblauch gebrauchen (CV V, 34). Er darf alle Medizinen nehmen (MV VI), Nonnen dürfen auch Fleisch erbitten (NPd 5-6). Daß dabei Kleinigkeiten kein Vorwand für Sonderrechte wegen Krankheit sein dürfen, wird bei der Reservierung von Schlaf plätzen ausgesprochen (CV VI, 10). - Krankheit anderer ist ebenfalls ein Erlaubnisgrund, nämlich zu Besuchen von Ordensangehörigen oder Eltern, auch ungebeten, dagegen von sonstigen Verwandten nur gebeten (MV III, $6-7)$.

Auch Unfälle oder Unglücksfälle im allgemeinen sind Entschuldigungsgründe, und zwar in 13 Fällen von $P(14-16,46,48-50,53,56,57,61,62,85)$, in einem Falle von $\mathrm{Ni}(24)$ und wiederum in 72 Fällen von Se, wobei dort die drei Ausnahmen aber diesmal andere sind als bei Krankheit (nämlich 5, 6, 67). Wiederum ist die Zahl bei den Nonnen erheblich größer, und diesmal kommt sogar eines der schweren Vergehen dabei vor (SA III). Die übrigen Fälle - außer Se, die identisch sind - sind: NNi 6-10, NP 10, 15-17, 21, 23-25, 34, 37, 38, 40, 41, 44, 48, 51, $56-59,68-70,77,78,84,85,90-94,96$. Es würde $\mathrm{zu}$ weit führen, hier die einzelnen Fälle zu analysieren und zu überlegen, warum Unglücksfälle manchmal neben Krankheit genannt sind und manchmal nicht und warum z. B. gerade bei manchen Delikten keine Nennung erfolgt. Im allgemeinen aber wird man sagen dürfen, daß in den genannten Fällen bei Unglücken vernünftigerweise keine Einhaltung der betreffenden Regel zu fordern ist.

Wieweit man den Begriff des „Unglücksfalles“ dabei auszulegen hat, mag ebenfalls offen bleiben. Zwei Beispiele von Notlagen werden jedenfalls extra genannt: $\mathrm{Da}$ heißt es, in Notzeiten und wenn niemand zum Erlauben da ist, dürften Mönche, die sich sonst nichts ohne Erlaubnis aneignen dürfen, sich selber den Genuß von selbstgepflückten Früchten erlauben (MV VI, 17 u. 21). In einem anderen Fall teilten ankommende Mönche sich die Früchte eines dem Orden gehörigen Mangobaumes, und als ihnen der Vorwurf des Stehlens gemacht wurde, entschuldigten sie sich mit Hunger, was der Buddha billigte (Pj II, 38).

\subsection{Wichtiger Grund}

Die allgemeinste Ausnahme von der Einhaltung einer Regel ist es, wenn gesagt wird, ein Vergehen liege nicht vor, wenn ein Grund für die Handlung vorliege (sati paccaye). In drei Fällen, die alle das Essen betreffen, wird dies als anāpatti genannt: übermäßig essen und andere dazu veranlasssen ( $P$ 35-36) sowie außer der Zeit Festes essen ( $P$ 37). Einmal wird diese Ausnahme sowohl unter anāpatti als auch im Tatbestand der Regel selber aufgeführt, nämlich beim Feuer machen (P 56). Einmal taucht diese Klausel nur im Tatbestand der Regel auf und wird bei den anāpatti-Klauseln nicht noch einmal wiederholt, nämlich beim Zusehen bei einer Heerschau ( $P$ 48). Im Pātimokkha der Nonnen kommt die Generalklausel als solche gar nicht vor. Dafür aber werden wichtige Gründe in concreto 
aufgeführt: Das Verbot von Schimpfworten ist nicht verletzt, wenn solche zu Lehrzwecken im Vortrag erwähnt werden (NP 19, 52, 53); das Verbot, keine Hausarbeit zu verrichten, ist nicht verletzt, wenn die Nonne dies für sich selber tut und kocht und wäscht (NP 44). - Eine ähnliche Generalklausel lautet „wenn etwas zu tun ist" (sati karaniye: P 50, 52, 53): dann darf der Mönch z. B. ein Heerlager besuchen (P 50) oder schwimmen (P 53).

Als ein wichtiger Grund wird manchmal auch angesehen, daß Streit, Spaltung oder Illegitimes entstehen könnte, wenn man etwas sonst Gebotenes täte. Dies ist ein Grund für die Entbindung von der Pflicht zu reden (P 12, Fragen beantworten; P 80, abstimmen) oder zu schweigen (P 64 über Vergehen anderer; ebenso NPj II). Dies entbindet auch von dem Verbot, jemand hinauszuweisen (NP 35) oder von dem Gebot, jemand zu suspendieren (MV X, 1). In all diesen Fällen wird eine Güterabwägung vorgenommen und dahingehend entschieden, daß Streit das größere Übel wäre und jene Entbindung von der Pflicht immerhin das kleinere Übel. In ähnlicher Weise gilt das Verbot, andere zu kritisieren, nicht, wenn diese den üblen Trieben von Willensgier, Haß, Verblendung und Angst folgen ( $\mathrm{P}$ 13, 81, NP 76).

Als ein „wichtiger Grund“, der von einer Strafe entbindet, wird einmal die Erreichung der Heiligkeit („Versiegung des Durstes“) angesehen. Der Mönch Channo, über den die Strafe verhängt worden war, daß niemand ihn wegen seines Hochmutes anreden durfte, war heilig geworden. Er bat nun, man möge die Strafe aufheben. Da erwiderte ihm Anando, nach dem Tode des Buddha, daß die Aufhebung mit der Heiligkeit eingetreten sei (CV XI, 1).

\section{Erwerb und Verlust der Mitgliedschaft ${ }^{36}$}

Beim Eintritt in den Orden verschwanden alle Kastenunterschiede, die soziale Stellung wurde bewußt abgelegt ${ }^{37}$. So wurde der buddhistische Orden zur ersten klassenlosen Gesellschaft. Die Ordensangehörigen nannten sich Weltbürger, wörtlich: Bürger der vier Himmelsrichtungen. $\mathrm{Da}$ die Ordensangehörigen der weltlichen Gerichtsbarkeit kraft Gewohnheitsrecht entzogen waren, war der Orden als „besonderes Gewaltverhältnis“ eine autonome Körperschaft. Die Aufnahme in diesen Kreis ist nicht nur mit der Aufnahme in irgendeinen Verein zu vergleichen, sondern ähnelt dem Phänomen der Einbürgerung im Staate. Es mag dabei erwähnt werden, daß z. B. der Eintritt als Mönch auf dem Berge Athos die griechische Staatsangehörigkeit verleiht ${ }^{38}$ oder daß die Ernennung zum Kurienkardinal die vatikanische Staatsangehörigkeit verleiht ${ }^{39}$. Es ließe sich auch an die besondere Stellung des Malteser-Ordens denken, der kein Staat ist, aber als Völkerrechtssubjekt doch eine eigene Staatsangehörigkeit kennt ${ }^{40}$. So gibt es also gewisse Vergleichsmöglichkeiten zum Status des buddhistischen Weltbürgers. Bei Einund Ausbürgerung spielen nun die folgenden Rechtsprobleme ${ }^{41}$ eine Rolle:

36 Das erste und umfangreichste Kapitel des Mahavagga (Mahākhandaka oder Pabbajja-khandaka) behandelt in 79 Abschnitten die Fragen der Ordenszugehörigkeit. Zur Vermeidung zahlloser Hinweise sei im

37 Vergl. Hecker, Das Leben des Buddha, Hamburg 1973, S. 309 .

38 Art. 105 der griechischen Verfassung v. 11. 6. 1975, ebenso alle griechischen Verfassungen seit 1927.

39 Hecker, Sammlung geltender Staatsangehörigkeitsgesetze (SGS), Bd. 21, Frankfurt 1958, S. 98.

40 Hafkemeyer, Der Malteser-Ritter-Orden, Hamburg 1956, S. 144 und 150; Prantner, Malteserorden und Völkergemeinschaft, Berlin 1974, S. 86 und 90.

41 Dazu Hecker, Das Leben des Buddha, Hamburg 1973, S. 228-240. 


\subsection{Zuständigkeit und Verfahren}

Am Anfang lag die Ordensaufnahme, die Einbürgerungskompetenz, beim Buddha selber. Er allein nahm neue Mönche auf, und zwar mittels der schlichten Formel: „Komm, o Mönch, führe den Reinheitswandel zur Leidensüberwindung“.

Als der Drang zu groß wurde, delegierte der Buddha schon im ersten Halbjahr diese Befugnis: Die Mönche - sie waren damals alle Heilige - durften ebenso wie er je einzeln ordinieren,und der Kandidat mußte erklären, daß er zum Erwachten, zur Lehre, zur Jüngerschaft Zuflucht nehme.

Nach einem Jahr seit Gründung wurde das Verfahren formalisiert und erweitert: Die Aufnahme erfolgte jetzt vor einer Gruppe von Mönchen, und es wurden Einwände geprüft. Schließlich entstand das heute noch übliche umfangreiche Aufnahmeritual mit zahlreichen Fragen, die von dem Kandidaten zu beantworten waren, also mit einer Art Prüfung. Der Anwärter mußte ausdrücklich selber die Ordensgemeinde um Aufnahme bitten.

Später wurde als weiteres Erfordernis für die Ordination gesagt, daß mindestens 10 Mönche dabei anwesend sein mußten (in Gebieten außerhalb der damaligen Hindukultur, wo nur wenige Mönche lebten, genügten 5).

Dann wurde festgelegt, daß alle bei der Ordination mitwirkenden Mönche bereits 10 Asketenjahre hinter sich haben mußten, wobei offenbar auch die Zeit bei anderen Asketengemeinschaften mitzählte. Nonnen mußten 12 Asketenjahre hinter sich haben (NP 74), und es mußte außerdem ausdrücklich ihre Ordinationsfähigkeit anerkannt sein (NP 75).

Als sich zeigte, daß selbst 10 Asketenjahre keine sichere Gewähr für die Qualifikation des Betreffenden zur Mitwirkung bei der Ordination boten, wurde ein ganzer Katalog von Fähigkeitsvoraussetzungen aufgestellt, gegliedert in 6x5 Punkte. Wenn der Aufnehmende kein Heiliger war, so mußte er doch mindestens den ersten Grad des Verständnisses (sotapatti) besitzen, was sich am Besitz von bestimmten Fähigkeiten zeigt: Vertrauen, Tatkraft, Achtsamkeit, Weisheit. Da das schwer nachprüfbar ist, wurde wie folgt konkretisiert: Der Ordinierende mußte bei sich und anderen Depression (Unlust) und aufgeregte Unruhe heilen können, mußte Irrtümer widerlegen können und sich auf Krankenpflege verstehen. Ferner war erforderlich, daß er den Vinaya genau kannte. Durch all das sollte gesichert werden, daß die neuen Mönche wirklich ausgebildet wurden und in das buddhistische Mönchstum hineinwachsen konnten. Verstöße gegen alle genannten Voraussetzungen machten indes die Ordination nicht nichtig, das Fehlende konnte nachgeholt werden. Nichtberücksichtigung der Ordinationsvoraussetzungen wurde aber beim Ordinierenden als leichtes Vergehen (dukata) qualifiziert.

\subsection{Noviziat}

Ursprünglich gab es keinerlei Noviziat. Alle wurden sofort als Vollmitglieder ordiniert. Später wurde aber differenziert. Wer schon Pilger war, mußte eine Probezeit von 4 Monaten durchmachen, ehe er aufgenommen werden konnte, und als $\mathrm{Be}-$ gründung gab der Buddha an, daß er manche Veränderlichkeit erfahren habe. Nur in zwei Fällen waren Asketen auch ohne jede Probezeit aufzunehmen: Erstens, wenn sie brahmanische Feuerverehrer waren, weil diese als ernsthaft Strebende 
bekannt waren; zweitens, wenn sie von Geburt Sakyer waren, also dem Stamme des Buddha angehörten - was vergleichbar ist mit der erleichterten Einbürgerung Konnationaler, die vom mehrjährigen Inlandswohnsitz dispensiert werden. Während Asketen (Pilger), außer in jenen zwei Fällen, zwingend eine Probezeit durchmachen mußten, in der sie sich zu bewähren hatten, mußten Laien ein Noviziat durchmachen, dessen Dauer aber nicht festgelegt, sondern dem Ermessen der Aufnehmenden überlassen war. Ein besonders befähigter Laie konnte also am gleichen Tag Novize und Mönch werden, was bei einem Pilger nicht zulässig war. Der Grund für diese Differenzierung dürfte darin liegen, daß ein Pilger sich zuvor sozusagen hauptberuflich in seine frühere Weltanschauung eingearbeitet hatte und daher in seiner nichtbuddhistischen Ansicht schon sehr eingefahren war. Er benötigte daher eine Entziehungskur von intellektuellen Neigungen, während der Orden nach dem ganzen System des Vinaya mehr auf Entziehung von weltlichen Neigungen eingestellt war.

Die Novizen übernahmen noch nicht alle Ordensregeln, waren auch nicht an der vierzehntägigen Uposatha-Versammlung zwecks Rezitation des Pātimokkha beteiligt. Sie übernahmen 10 Tugendregeln (Sila), nämlich 5 auch für buddhistische Laien geltende, wobei das Gebot, Ausschweifung zu vermeiden, zum Gebot der Keuschheit erweitert wurde, außerdem noch 5 mönchische Regeln: nach Mittag nichts essen, kein Geld annehmen, keine Zerstreuungen besuchen, sich nicht herausputzen, keine prächtigen Lager benutzen.

Eine Besonderheit im Nonnenorden war, daß dort dem Noviziat noch eine Vorschule vorgeschaltet war. Bevor eine Frau Novizin werden konnte, mußte sie 2 Jahre lang sich in der Einhaltung von 6 Regeln üben: die 5 Tugendgebote (einschließlich Keuschheit) und nach Mittag nichts essen. Diese sog. Übende (Sikkhamana) durfte also sogar noch Geld besitzen.

\subsection{Ordinationsvoraussetzungen}

Es wird ein Katalog von Tatbeständen aufgezählt, bei denen eine „Einbürgerung“ im Orden nicht vorgenommen werden sollte. Selbst wenn alle Einbürgerungsvoraussetzungen gegeben sind, besteht doch kein Aufnahmeanspruch, sondern dies ist Ermessenssache, ganz ebenso, wie es in der Regel bei der Einbürgerung im Staate der Fall ist, der einen Einbürgerungsanspruch nur sehr zögernd gewährt ${ }^{42}$.

1. Alter: Das Mindestalter für die Ordination ist 20 Jahre, da erst dann die Strapazen der Askese gemeistert werden können, was bei Jüngeren selten der Fall ist. Als Novize kann man allerdings schon mit 15 Jahren aufgenommen werden. Ausnahmsweise kann bei Frühreife auch schon jemand unter 15 Novize werden ${ }^{43}$. Diese Ausnahme ist heute in Asien die Regel, indem dort überall Kinder schon zum Noviziat zugelassen werden.

2. Zustimmung Dritter. Personen, die in irgendeinem betonten Abhängigkeitsverhältnis, einem „besonderen Gewaltverhältnis“ stehen, bedürfen der vorherigen $\mathrm{Zu}$ stimmung des Gewalthabers, bevor sie ordiniert werden können. So bedürfen Minderjährige der Zustimmung der Eltern. Eine Einwilligung der Ehefrau ist -

42 Ưber die zeitlich begrenzten Fälle eines Einbürgerungsanspruchs in Deutschland s. SGS Bd. $35, \mathrm{~S} .114 \mathrm{f}$.

$43 \mathrm{Zu}$ dieser eigenartigen Regelung siehe Hecker, a. a. O., S. 234. In Ceylon wird ein Alter von nur 8 Jahren für ausreichend gehalten (Härtel, S. 65 Anm. 3). 
anders als in christlichen Orden - bei Männern nicht erforderlich, wohl aber bei Ehefrauen Einwilligung des Mannes (NP 80; CV X, 17). Sklaven bedürfen der Zustimmung ihres Herrn, ebenso bedürfen im Staatsdienst Stehende, insbesondere Soldaten, der Zustimmung des Königs. Die Ordination von Soldaten galt vor der Zeit des Buddha als ein besonders schweres Vergehen: der Aufnehmende wurde enthauptet. Obwohl der buddh. Orden der weltlichen Gerichtsbarkeit entzogen war, beanspruchte der König dieses Recht weiterhin, um eine Flucht vom Militärdienst in den Orden durch solche abschreckende Strafe zu unterbinden.

3. Weltanschauung. Die frühere Weltanschauung des Betreffenden ist als solche nie ein Hinderungsgrund. Wer jedoch als buddhistischer Mönch austrat und in einen anderen Orden eintrat, durfte nicht wieder als Buddhamönch aufgenommen werden. Ebenso bei Nonnen (CV X, 26) galt das als Verwirkung. Im übrigen war, wie erwähnt, bei Pilgern nur eine Probezeit nötig. Wer sich während der Probezeit ungehörig benahm, war dann deswegen von der Ordination ausgeschlossen, nämlich, wenn er keinen Eifer beim Lernen und Üben zeigte, wenn er bei Kritik an seiner früheren Weltanschauung dafür Partei ergriff, wenn er sich herumtrieb. 4. Erschleichung: Wer sich selbstherrlich zum Buddhamönch gemacht hatte, indem er das Ordensgewand ohne Ordination trug, der durfte nicht ordiniert werden. Eine derartige Eigenmächtigkeit machte ungeeignet, sich in die Ordnung einzufügen.

5. Moral: Ebensowenig wie das geistige Vorleben war auch das moralische Vorleben in der Regel kein Hinderungsgrund für die Aufnahme - beides im Unterschied zur Einbürgerungspraxis der Staaten. Nur in einigen krassen Fällen bestand eine Aufnahmesperre:

Wer im Orden des Buddha eines der 4 Ausschlußvergehen begangen hatte, durfte in diesem Leben nicht wieder ordiniert werden.

Wer als Novize gegen seine 5 Tugendgebote verstieß, falschen Ansichten nachging und den Buddha, die Lehre und Gemeinde herabsetzte, durfte nicht ordiniert werden, sondern mußte austreten.

Wer eines von fünf Arten von Verbrechen beging (Mord an Vater und Mutter und Heiligen, Körperverletzung an einem Buddha, Ordensspaltung) oder eine Nonne verführt hatte, verwirkte die Möglichkeit, ordiniert zu werden.

Ausgebrochene Häftlinge, zum Tode Verurteilte, steckbrieflich gesuchte Verbrecher, gebrandmarkte Diebe und fortgelaufene Sklaven durften nicht ordiniert werden, um einen Konflikt des Ordens mit der Obrigkeit zu vermeiden. Daß es dabei nicht um die Taten selber ging, zeigt sich daran, daß bei Zustimmung des Staates dann eine Aufnahme möglich war.

6. Körpermängel: Dauernde körperliche Gebrechen wie Altersschwäche, Blindheit, Taubstummheit, Amputation, Hinken sind ein Grund, die Aufnahme abzulehnen. Zeitweise Hindernisse wie ansteckende Krankheiten oder Schwangerschaft oder Säugen hinderten die Aufnahme nur während der betr. Zeit. Ferner durften nicht aufgenommen werden: Eunuchen, Zwitter und Nāga-Gottheiten. 


\subsection{Ausbürgerungsgründe}

Fehler bei den Einbürgerungsvoraussetzungen sind in den meisten Fällen zu beheben, d. h. der Betreffende blieb im Orden und konnte die Voraussetzungen nachholen. Eine Ordination ohne das Vorliegen aller Voraussetzungen war für den Ordinierenden nur ein leichtes Vergehen (dukata). Das Fehlen von Voraussetzungen machte nur in zwei Fallgruppen die Ordination nichtig, so daß der Betreffende nie als Ordensangehöriger galt:

Wenn erstens jemand sich eigenmächtig die Robe angezogen hatte oder wenn Eunuchen, Zwitter und Nāgas ordiniert worden waren, dann wurde die Nichtigkeit des Tragens des Mönchsgewandes ex tunc festgestellt, und der Betreffende durfte auch lebenslänglich nicht wieder aufgenommen werden.

Wenn zweitens jemand im Alter unter 20 Jahren ordiniert worden war, dann wurde die Nichtigkeit dieser Ordinierung festgestellt. Im Gegensatz zum vorigen Fall konnte der Betreffende aber als Novize im Orden bleiben und bei Erreichung des Ordinationsalters neu aufgenommen werden. Weil die erste Ordination nichtig war, zählte sie auch bei der Berechnung der Ordensjahre nicht mit.

In zwei weiteren Fällen, die eine gültige Ordination voraussetzten, gab es später eine "Ausbürgerung", die dann aber nicht rückwirkende Kraft hatte, d. h. ,die Ordenszugehörigkeit endete von einem bestimmten Zeitpunkt ab:

Wer die vier Ausschlußvergehen ( $\mathrm{Pj}$ ) begangen hatte, galt mit der Begehung als nicht mehr dem Orden zugehörig. Das wurde dann vom Orden festgestellt. Der derart wegen Verwirkung der Mitgliedschaft strafweise Ausgebürgerte durfte lebenslänglich nicht wieder aufgenommen werden.

Der Ordensangehörige konnte schließlich auch von sich aus und ohne Angabe von Gründen jederzeit wieder austreten. Im Gegensatz zu christlichen Orden gab und gibt es im buddhistischen Orden keine lebenslangen Gelübde. Die Ordensangehörigen legten Gelübde nur für die Dauer ihrer Zugehörigkeit ab. Wer dann ausgetreten war, konnte aber jederzeit wieder eintreten, falls er nicht $\mathrm{zu}$ andersfährtigen Pilgern übergegangen war. In einem Fall wird sogar berichtet, daß ein Mönch nicht weniger als siebenmal ein- und austrat, aber dann schließlich doch als Mönch ein Heiliger wurde (A VI, 60).

\section{Streit und Streitschlichtung}

Ein Gebiet, das innerhalb jeder menschlichen Gemeinschaft der Regelung bedarf, ist das Problem der Meinungsverschiedenheiten, des Streites, der Auseinandersetzungen. In verschiedenster Weise sind hierüber Bestimmungen notwendig, sei es, daß bestimmte streitfördernde Verhaltensweisen zu Straftatbeständen erklärt werden, sei es, daß Disziplinarmaßnahmen als Verwaltungsakte erlassen werden, sei es, daß Vorschriften für ein allgemeines Schlichtungsverfahren entwickelt werden, einschließlich Verteilungsprinzipien und Rangordnungen, die festzulegen sind. 


\subsection{Auflehnungstatbestände}

Drei verschiedene Spielarten von Auflehnung gegen die allgemeine Ordnung der Gemeinschaft lassen sich innerhalb der Regeln unterscheiden:

1. Aktive Kritiklust: Wer in einer Versammlung einem Verwaltungsakt (z. B. Verteilung von Roben) zustimmt, aber hinterher die Versammlung der Parteilichkeit bezichtigt, der Korruption und Vetternwirtschaft, der ist nicht nur feige gewesen, sondern er benimmt sich untragbar. Dies ist ein Aufhetzen anderer gegen die Ordnung, es ist völlig destruktiv und illegal. $\mathrm{Da}$, wo man hätte legal mitwirken können, da versäumt man es, weil man fürchtet, überstimmt zu werden; und da, wo die Mitwirkungsmöglichkeit beendet ist, da lehnt man sich als „Außerparlamentarische Opposition" gegen die Verfassungsordnung auf. Daher ist dies ein zu beichtendes Vergehen (P 81).

Wenn gegen eine Gruppe verhandelt wird und diese einen Bevollmächtigten in die Sitzung schickt, deren Urteil dann gegen ihn ausfällt, dann ist es untragbar, wenn die Gruppe nun rückwirkend die Vollmacht widerruft. Zuerst beugte man sich der Ordnung und unterwarf sich der Gerichtsbarkeit: als diese sich aber ungünstig aussprach, da revoltierte man gegen die Ordnung und behauptete durch ein juristisches Manöver, man sei gar nicht vertreten gewesen. Es ist ein typischer Fall des venire contra factum proprium. Das ist ebenfalls ein zu beichtendes Vergehen (P 79).

Der Antrag eines $\mathrm{X}$ wird von der zuständigen Versammlung abgelehnt, und $\mathrm{X}$ unterwirft sich auch dem Spruch. Als aber der Antrag von $\mathrm{Y}$ genehmigt wird, protestiert $\mathrm{X}$ und behauptet, der Gleichheitsgrundsatz sei verletzt, obwohl der Fall anders lag. Ein solcher Mißbrauch der Berufung auf den Gleichheitsgrundsatz wird bei den Nonnen gesondert als Vergehen aufgeführt (NP 76).

Der extremste Fall des Anarchismus ist es, wenn Menschen, die die Ordnung verabscheuen und sich in keiner Weise unterordnen mögen, nun einen Verleumdungsfeldzug gegen die Ordnung entfachen. Ihre Schlagworte lauteten damals seltsam bekannt: „Verbote führen bloß zu Schuldgefühlen, zu Repression und Verdrängung. Wozu werden solche Kleinigkeiten geregelt, das ist doch lächerliche Kasuistik. Solche Regeln sollte man straks aufheben." Der Buddha legte fest, wer derart während der Rezitation des Pātimokkha die Übung herabsetze, der begehe ein Vergehen (P 72).

2. Passiver Widerstand: Außer der revolutionären Opposition („aktive Kritiklust“) gibt es auch noch eine destruktiv zersetzende Opposition („passiver Widerstand“): Wenn einem in einer Versammlung peinliche Fragen, unangenehme Tagesordnungspunkte drohen, dann kann man die Versammlung dadurch beschlußunfähig machen, daß man davonläuft. Man verläßt den Sitzungssaal und lähmt durch diese Obstruktion das weitere Verfahren (P 80). Der Fall des Allierten Kontrollrats in Berlin ist ein klassisches Musterbeispiel, und ebenso manche UNO-Sitzungen. Im Grunde ist dies ein Schwächezeichen, ein Nichtverlierenkönnen - nicht viel anders, als wenn Kinder beim Spiel davonlaufen, falls ihnen etwas nicht paßt.

Ahnliche Obstruktion ist es, wenn man zwar nicht aus dem Sitzungsraum herausläuft, aber die Aussage verweigert, keine Stellungnahme abgibt, heilloses Schweigen übt - ebenso wie wenn man einen Brief nicht beantwortet. Dieses beredte Schweigen ist wiederum passiver Widerstand, ein Protest des Schwachen (P 12, Fall 2). 
Ebenfalls ein Vergehen ist es, wenn jemand eine Entschuldigung eines andern nicht annimmt und ihn weiter mit schlechtem Gewissen herumlaufen läßt. Er verweigert hier eine Schlichtung durch den Gnadenakt der Verzeihung. Das ist ebenso schädlich, wie wenn man sich aus Trotz selber nicht entschuldigt. Beides ist dukata (MV I, 27).

Passiver Widerstand ist es auch, trotz dreimaliger Abmahnung überhaupt nicht hinzuhören, d. h. wiederholten Vorhaltungen trotzen, sich nichts sagen lassen und so tun, als sei nichts geschehen. Ein solcher tut das Beanstandete nun gerade weiter, er meutert, begeht Befehlsverweigerung. Das wird bei verschiedenen Tatbeständen als Vergehen aufgefaßt (SA X, XI, XIII, P 68; NPj III, NSA VII-X, NP 36).

3. Eigenmächtigkeit: Eine dritte Weise des Auflehnens besteht darin, daß man gar nicht erst fragt, um sich nicht der Gefahr der Ablehnung auszusetzen. Auch das ist die Furcht des Schwachen. Man schafft hier vollendete Tatsachen (fait accompli) und vertraut dann auf die normative Kraft des Faktischen. Von den hierher gehörenden 13 Regeln des Kanons betreffen die meisten Nonnen: Eigenmächtigkeit ist es, jemanden vorzeitig zu begnadigen (rehabilitieren), um sich bei ihm lieb Kind zu machen (NSA IV). Eine Rehabilitation ist nur durch eine Versammlung von 20 Mönchen möglich (MV IX, 4).

Eigenmächtigkeit ist es, auszugehen, ohne zu sagen, wohin (P 85) bzw. als Ordensangehöriger ungenehmigt mit dem andern Geschlecht umzugehen (P 21, NP 51, 60, 94, 95).

Eigenmächtig ist es, ohne Rücksicht auf die erforderlichen Gremien jemand $z u$ ordinieren (NSA II, NP 64, 67, 73, 75).

\subsection{Arten von Disziplinarmaßnahmen}

Im Vinaya werden zahlreiche Akte (kamma) genannt, die sowohl in streitigen wie unstreitigen Fällen vorkommen. Darunter sind sieben Arten von Disziplinarmaßnahmen, die bestimmte Fälle regeln (CV I). Gegen wen diese Maßnahmen verhängt sind, der darf 18 Dinge nicht tun, er darf insbesondere nicht ordinieren, darf keine Schüler haben, darf nicht lehren, nicht befehlen, nicht andere ermahnen usw. Der erste dieser Akte ist eine Mißbilligung, eine öffentliche Rüge für bestimmte Verhaltensweisen (tajjaniya-kamma), sozusagen als letzte Verwarnung vor strengeren Maßnahmen. In fünf Fällen ist dies angebracht: wenn Streitsüchtige andere zu Ungehorsam und Streitereien aufhetzen; wenn jemand viel Vergehen beging und noch nicht davon frei ist, aber nur falls er unweise ist; wenn jemand in unzulässigem Kontakt mit Laien lebt; wenn er von Tugend, Wandel und Anschauung abgefallen ist; wenn er verächtlich vom Buddha, von der Lehre und der Gemeinde spricht.

Der zweite dieser Akte stellt jemand, auf den die Fälle Nr. 2-3 oben zutreffen, unter Vormundschaft (nissāya-kamma), d. h. er muß in strenger Abhängigkeit von einem anderen Mönch leben, wird in seiner Freiheit sehr eingeschränkt.

Der dritte Akt ist noch wiederum eine Steigerung, nämlich Verbannung von einem Ort wegen ungewöhnlich schlechten Benehmens in Werken und Worten (pabbajaniya-kamma), und zwar bei Amüsement, ungeziemendem Verhalten, Verletzen anderer und falschem Lebensunterhalt.

Der vierte Akt befiehlt jemandem, einen anderen um Verzeihung zu bitten 
(patisaraniya-kamma), und zwar muß hier stets ein Mönch bei Hausleuten um Verzeihung für sein Verhalten ihnen gegenüber bitten, nämlich wenn er bei ihnen anderen Gaben, Ehre und Wohnung abspenstig macht, wenn er die Hausner beleidigt, wenn er zu Zwietracht unter ihnen aufhetzt, wenn er den Buddha, die Lehre und Jüngerschaft ihnen gegenüber tadelt, wenn er sein Wort bricht.

Der fünfte Akt befiehlt, daß jemand, der hartnäckig einen Verstoß nicht einsehen will, nicht mit anderen zusammen essen darf und daß anderen verboten wird, mit ihm Gemeinschaft beim Essen zu pflegen (ukkhepaniya-kamma). Ein solcher darf, zusätzlich zu den 18 oben genannten Dingen, noch weiteres nicht tun: er darf keine Dienste von anderen entgegennehmen, darf nicht mit den Ordensbrüdern zusammen unter einem Dach übernachten, hat vor anderen Mönchen aufzustehen usw. Ein gleiches gilt, wenn der Betreffende bei einem Verstoß eine Wiedergutmachung verweigert oder wenn, als 7. Fall, jemand eine falsche Ansicht hartnäckig nicht aufgibt. In all diesen drei Fällen wird er gebrandmarkt und zeitweise relativ exkommuniziert.

Nahe damit zusammen hängt, daß ein Mönch, der eine Probezeit durchmacht, ebenfalls jene 18 Dinge nicht tun darf, zuzüglich folgender: er muß immer den letzten Platz einnehmen, darf keine besonderen Praktiken, insb. Waldeinsiedlertum, wählen, darf nicht die Unterstützerfamilien eines andern Mönches aufsuchen, muß überhaupt sich stets melden, wenn er kommt, wenn er krank wird usw. (CV II).

\subsection{Streitschlichtungsverfahren}

Am Ende des Pātimokkha, als die Regeln Nr. 221-227, werden sieben Weisen genannt, wie Streitigkeiten zu schlichten sind ${ }^{44}$. Während die Regeln Nr. 1-220 sozusagen das Strafgesetzbuch des Ordens enthalten, sind diese letzten Vorschriften solche des Verfahrens, jedoch nicht nur eines Strafverfahrens, sondern eher allgemeine Grundsätze für jedes Verfahren, das zur Streitschlichtung dient.

Zunächst werden die vier Möglichkeiten genannt, deretwegen überhaupt im Orden Streitfragen entstehen können, nämlich erstens aus Meinungsverschiedenheit über Lehre und Ordnung, zweitens aus kritischen Äußerungen gegen andere, drittens anläßlich der Frage, ob jemand ein Vergehen begangen hat oder nicht, und schließlich viertens wegen der Frage, ob eine bestimmte Pflicht im Orden besteht oder nicht. Bei jedem dieser vier Anlässe wird nun gesagt, durch welche der sieben Streitschlichtungsmethoden der Fall zu regeln ist.

a) Das erste Prinzip des Verfahrens ist die Anwesenheit des jeweils Beschuldigten und ordnungsgemäße Verkündung von Antrag und Entscheidung in seiner Gegenwart. Alle Akte, die in Abwesenheit des Betroffenen ergehen, sind nichtig: es gibt keine Verurteilung in contumaciam (MV IX, 6). Auch wenn der Betroffene nachträglich durch Überredung dazu gebracht werden sollte, dem Verfahren zuzustimmen, bleibt es nichtig. Bei allen vier Anlässen muß Anwesenheit vorliegen. In diesen Zusammenhang gehört auch noch das Prinzip der Vollständigkeit der jeweili-

\footnotetext{
44 Diese "Adhikarana“ werden erörtert in CV IV; kürzer u. teils in anderer Reihenfolge in der 104. Rede der Mittleren Sammlung. Parivāro IX (Adhikarana-bheda) enthält nichts Bemerkenswertes dazu. In Anguttara-Nikāya VII, 80 sind die 7 nur aufgezählt. Näher behandelt bei Dutt, Early Buddhist Monachism, 1960, S. 113-145 im Kapitel „Internal polity of a Buddhist Sangha“.
} 
gen Gemeinde bei Verwaltungsakten, das sehr genau eingeschärft wurde. Akte einer unvollständigen Versammlung waren stets nichtig. In gewissen Fällen war Höchstpersönlichkeit vorgeschrieben: wenn ein Kranker keinen Beauftragten schicken konnte, mußte er notfalls auf einer Bahre zur Versammlung getragen werden, oder wenn er nicht transportfähig war, mußte die Versammlung zu ihm hingehen und dort tagen (MV II, 22).

b) Das zweite Prinzip ist die Rechtskraft. Wenn jemand rechtskräftig freigesprochen wurde und andere ihn aber weiterhin als schuldig behandeln und somit das Urteil mißachten, indem sie sich selber zum Richter aufwerfen, dann kann auf Antrag des Betroffenen verboten werden, daß andere ihn als schuldig bezeichnen. Es wird hiermit das Prinzip der res iudicata ${ }^{45}$ noch einmal ausdrücklich festgestellt. Diese zweite Streitschlichtung gibt es nur bei Vorwürfen. Außerdem ist es ein Vergehen, wenn jemand verlangt, daß ein rechtskräftig abgeschlossener Prozeß neu aufgerollt würde (P 63), oder wenn jemand einem Verfahren erst zustimmte, es dann aber hinterher anficht (P 79).

c) Das dritte Prinzip verbietet in entsprechender Weise, daß man jemanden, der in momentaner Unzurechnungsfähigkeit aus Geisteskrankheit Vergehen beging, als Täter bezeichnet und ihm Vorwürfe macht. Unzurechnungsfährigkeit schließt eben die Schuld aus. Hier wird also ausdrücklich vom Orden festgestellt, daß der Betreffende für seine Taten während des Zustandes der Geisteskrankheit nicht verantwortlich war, und es wird verboten, daß man ihn als zurechnungsfähig dafür behandelt. Auch dies gibt es nur bei Vorwürfen.

d) Das vierte Prinzip verbietet Verurteilung ohne Geständnis, und dies gibt es nur bei Vergehen. Dies Prinzip verhindert Willkürakte, Justizkomëdien und Schauprozesse. Auf den Gedanken, daß man jemand durch Folter zum Geständnis zwingen könnte, ist im Buddhismus niemand gekommen. Besonders bei den Disziplinarmaßnahmen wird hervorgehoben, daß ein Verhör voranzugehen hat, samt Überführung (MV IX, 5 und CV I, 3 ff.).

e) Das fünfte Prinzip ist die Mehrheitsentscheidung, die es nur bei Meinungsverschiedenheiten über Lehre und Ordnung gibt. Wo es dagegen um einen einzelnen Menschen und sein Verhalten geht, genügt also die Mehrheit nicht, sondern es gilt das Konsensprinzip, d. h. in dubio pro reo, auch wenn von mehreren zur Entscheidung Berufenen nur einer Zweifel hat. Wenn man sich nämlich über eine Maßnahme gegen eine Person nicht einig ist, ist es zu verkraften, wenn die Maßnahme unterbleibt. Es ist aber unmöglich, daß für die Zukunft und für den Orden offen bleibt, wie eine Frage von Lehre und Ordnung abstrakt zu entscheiden ist. Kurz gesagt gilt also folgendes: Bei der Legislative Mehrheit, in der Rechtsprechung und Verwaltung Einstimmigkeit. Das ist ein bemerkenswerter Grundsatz. Über das Verfahren zur Bildung der Mehrheitsentscheidung wird im einzelnen folgendes gesagt: Wenn die Mönche sich hier nicht einigen können, sondern in scharfe Wortgefechte verfallen, dann sollen sie in größerem Rahmen zusammenkommen und dort zu einer Abstimmung schreiten, und zwar durch Stimmzettel. Die Abstimmung soll geheim erfolgen - offen soll sie nur erfolgen, wenn der Abstimmungsleiter sicher ist, daß die Mehrheit für die richtige Entscheidung ist. Es werden dann zehn Fälle aufgezählt, bei denen nicht zu einer Mehrheitsentscheidung gegriffen werden soll: bei bloßen Kleinigkeiten, wenn der Streit noch nicht um sich ge-

45 So ausdrücklich Dutt, 1962, S. 88. 
griffen hat, wenn er schon wieder vergessen ist, wenn der Abstimmungsleiter weiß oder vermutet, daß eine lehrwidrige Mehrheit zustande kommen wird oder gar eine Spaltung der regionalen Gemeinde, wenn die Abstimmungszettel nicht gültig verteilt sind, wenn die Versammlung unvollständig war und wenn die Abstimmung unecht war, weil die Betreffenden ihre wahre Meinung aus Sympathie oder Angst wechselten. Dazu werden im einzelnen noch genauere Vorschriften gegeben. Eine Ordenspaltung gibt es z. B. nur bei mindestens neun Personen: wenn sich vier und vier Mönche gegenüberstehen und der neunte auf eine Seite tritt, dann kann die Gruppe von fünf Mönchen sich abspalten und eigne Ordensakte vollziehen ${ }^{46}$

f) Das sechste Prinzip ist, daß Prozeßverschleppung ein Riegel vorgeschoben wird. $\mathrm{Da}$ gesteht einer, widerruft dann wieder, gesteht auf Vorhalt etwas Belangloses statt der begangenen schwerwiegenden Tat, macht Ausflüchte, indem er erklärt, das Abstreiten sei nur aus Scherz erfolgt usw. In solchen Fällen soll nicht weiter verhandelt werden, sondern es hat zunächst ein Urteil wegen Prozeßverschleppung gegen den Betreffenden zu ergehen. Dies Verfahren wird genannt „Die schlimmere Weise", es ist sozusagen ein Notbehelf. Voraussetzung ist, daß der Betreffende unrein war, schamlos (insb. beim Lügen) und daß Vorwürfe vorliegen, indem nämlich dieses Verfahren nur bei Vorwürfen zulässig ist, und zwar Vorwürfe wegen Streitsucht und wegen ungeziemender Gesellschaft mit Laien.

g) Das letzte Prinzip heißt „Gras darüber streuen“, und es kommt nur bei Vergehen vor. Wenn während eines Streites manches an Vergehen geschah, dann würde das Aufrollen aller Einzelheiten nur zu größerer Spannung oder gar Spaltung führen. Falls nicht Laien beleidigt wurden oder schwere Vergehen ( $\mathrm{Pj}, \mathrm{SA}$ ) vorlagen, soll eine Amnestie erlassen werden, und man soll gegenseitig auf Durchführung von Prozessen verzichten, um so einen „Allgemeinen Landfrieden“ herzustellen.

\subsection{Rangordnung}

Auch in einer klassenlosen Gesellschaft wie der der Mönche, wo eine derartige Gleichberechtigung aller Mitglieder galt, daß die Kaste keinerlei Rolle mehr spielte, gab es beim alltäglichen Zusammenleben doch Fragen einer Rangordnung. Sollte dabei das Lebensalter oder das "Dienstalter" der im Orden verbrachten Jahre gelten oder sonstige Gesichtspunkte?

Als Grundsatz läßt sich feststellen, daß das Lebensalter, welches vom Buddha für Laien als Maßstab der Achtung hingestellt wurde, im Orden keine Rolle spielte. Je länger jemand unter der Disziplin des Ordens gestanden hatte, desto wahrscheinlicher war es, daß er weniger langgedienten Mönchen an Erfahrung überlegen war. Wenn im Vinaya daher von Seniorität (yatha-vuddha = gemäß dem Alter) die Rede ist, dann ist immer nur das Dienstalter gemeint, während im bürgerlichen Leben das Lebensalter entschied.

Das Dienstalter wurde besonders für die Beteiligung an Verwaltungsakten des Ordens wichtig. Je länger jemand im Orden war, desto verantwortungsvollere

46 So CV VII, 5. Die richtige Auslegung dieser Stelle gegenüber Horner Part V, S. 286 Anm. 5 bei Bechert, "Asokas ,Schismenedikt" und der Begriff Sanghabeda“, in: WZKSO 1961 (Bd. 5), S. 18-52, hier S. 32 ". 
Entscheidungen durfte er mittragen. So wurden für die Teilnehmer an den wichtigsten Beschlüssen zehn Dienstjahre (Thera) erfordert (MV I, 31) und erst nach 20 Jahren wurde einer Mahāthera.

Ebenfalls galt das Dienstalter für Akte der Courtoisie: der jüngere Mönch hatte den Älteren mit dem indischen Handgruß zu grüßen, ihn ehrfürchtig zu behandeln, ihm den besten Sitz und die beste Almosenspeise anzubieten (CV VI, 6). Besonders wurde dies betont, wenn ein älterer Mönch in einem Kloster eintraf: Ihm sollte aufgewartet werden (CV VIII, 2). Als der Buddha einmal fragte, wem der beste Sitz und die beste Nahrung gebühre, da gaben die Mönche verschiedene Antworten: Die einen waren für die beiden oberen Kasten, andere für Sprecher der Lehre und Zucht, andere für Meditationserfahrene, andere für die Heiligkeitsgrade. Der Buddha aber sagte, so wie unter Tieren das Lebensalter den Vorrang hat, so solle es im Orden das Dienstalter sein (CV VI, 6).

In einigen Fällen wurde das Behandeln nach Dienstalter jedoch verboten und in der Regel zu einem leichten Vergehen (dukata) erklärt:

1. Wenn die Mönche unbekleidet wie im Badehaus waren, sollten sie sich nicht nach Seniorität grüßen $(\mathrm{CV} \mathrm{V}, 15)$ und ebenso sollte beim Warten vor dem Abort nicht Seniorität gelten (CV VIII, 10).

2. Ordenseigentum durfte nicht nach Seniorität reserviert werden, und ebensowenig was vorgesehen war, Ordenseigentum zu werden (CV VI, 7).

3. Diejenigen, die Suspensionsstrafen unterlagen, verloren solange die Seniorität und galten als eben erst ordiniert.

4. Seniorität galt nur innerhalb des Mönchsordens, aber nicht im Verhältnis zu Nichtordinierten (Laien, Pilger, Novizen) und auch nicht zu Nonnen (CV X, 3).

5. Wenn jemand zu einer anderen Ordensgruppe gehörte und nicht der Lehre gemäß lehrte, sollte er trotz Seniorität nicht gegrüßt werden. Innerhalb derselben Gruppe war er also trotzdem nach Seniorität zu behandeln.

\subsection{Verteilungsprinzipien}

Wenn ein Laie ausdrücklich sagte, er wolle etwas für „beide Orden“ spenden (d. h. für Mönche und Nonnen), dann mußte es je zur Hälfte dem Mönchsorden und dem Nonnenorden übergeben werden, ganz gleich wie viele Mitglieder jeweils vorhanden waren. Selbst wenn viele Mönche und nur eine Nonne da waren, dann galt das Prinzip der Gleichheit beider Orden als Empfänger (MV VIII, 32). Wenn eine Nonne etwas „dem Orden“ vermachte, dann galt dies für den Nonnenorden allein, ebenso entsprechend umgekehrt beim Mönch. Wenn dagegen ein Laienanhänger oder eine Laienanhängerin etwas „dem Orden“ vermachte, dann galt dies allein für den Mönchsorden (CV X, 11).

Grundsätzlich erbt der Orden Mantel und Schale eines verstorbenen Mitglieds. Aber ein Mönch oder auch ein Novize kann beides dem vermachen, der ihn bei Krankheit pflegte. Wenn ihn ein Mönch und ein Novize pflegten, dann konnte er es ihnen je zur Hälfte vermachen. Was aber ein Mönch darüber hinaus an Besitz haben sollte, das konnte er nicht anderen vererben, sondern es fiel an den Orden (MV VIII, 27).

Es bestand ein Verfügungsverbot an fünf Dingen des Ordenseigentums: Kloster, Wohnplatz, Betten, Werkzeuge aus Metall und aus anderem (CV VI, 15). 
Bei Stoff, den der Orden zur Verteilung an die Mönche erhielt, ist dieser nicht nach der Reihenfolge der bei der Verteilungsstätte Eintreffenden zu verteilen, auch nicht nach Lebens- oder Dienstalter, sondern durch das Los (MV VIII, 9).

$*$

Abschließend läßt sich sagen, daß die buddhistische Ordensverfassung eine ganze Reihe allgemeiner Rechtsgrundsätze enthält, die in der europäischen Kultur z. T. erst Jahrhunderte oder Jahrtausende später als besondere Errungenschaften eines fortschrittlichen Rechtsdenkens eingeführt wurden. Was Miss Horner von den Strafausschließungsgründen sagt, daß sie "are all remarkable for their humane and

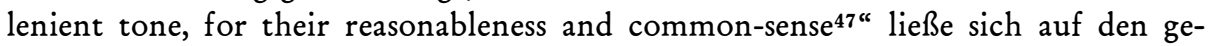
samten Vinaya anwenden ${ }^{48}$.

47 Vinaya, Part V, S. XXXVI.

48 In seiner jüngsten Veröffentlichung unterstreicht auch Bechert die Bedeutung des Vinaya, den er "das älteste uns erhaltene indische Rechtsdenkmal“ nennt (Weltflucht oder Weltveränderung: Antworten "des buddhistischen Modernismus auf Fragen unserer Zeit, Göttingen 1977, S. 8). 
remained up to the present relatively unchainged, insofar as its functions for the production process were concerned. As a new function, the state has to mobilize revenues in different ways. This increases even more the dependence from metropolitan capitalism. The typical form of the alliance of interests between the local power elite and the international bourgeoisie is the parastatal sector, which is shown by examples from Tanzania and Zambia.

Today we face a silent class struggle between the westernized bureaucratic bourgoisie and its international partners (multinational corporations) on the one hand and industrial workers (Nigeria), kulaks and other social classes on the other hand. The local state in LDC is thereforde in a stage of siege. Hope for changing the present power structures in Black Africa is small.

\section{General Principles of Law in the Constitution of the Buddhist Order (Vinaya)}

\section{By Hellmuth Hecker}

The "Vinaya" (Constitution of the Buddhist Sangha) is one of the most ancient legal documents about the social life of human society. This order emerged 2500 years ago in North India. It's rules which are traced back to Buddha himself have been taken over, with only little accommodations, by all Buddhist schools, as well in South-East-Asia as in Tibet or China. The Vinaya is divided into two parts. The first part contains a wealth of special commandments and permissions. The second part contains 227 numbered rules which form the Penal Code of the order (the so-called Pãtimokkha). The Pãtimokkha is divided into eight categories according to the gravity of the act. Each of the 227 rules is set up according to a uniform scheme which also contains terminological definitions and a collection of cases.

Three fields that show general principles of law have been selected here out of the richness of rules in both parts of the Vinaya:

1. Reasons for exemption from punishment within the Pãtimokkha. Even at that time the principle "nullum crimen sine lege" had been determined explicitly. Furthermore the following subjects are treated: irresponsibility, absence of criminal intent, interruption of attempt, permission, relationship, or parapsychological fact, influence of illness and accidents, as well as other important reasons.

2. Acquisition and forfeiture of membership in the order, which is comparable to the acuisition or forfeiture of nationality. Here are treated: competency, procedure, admission of novices, general conditions of ordination, causes for expatriation (facts of forfeiture).

3. Conflicts and their settlement. Here are illustrated several facts which are considered as a breach of peace. Then follows the description of seven ways of disciplinary measures for the maintenance of order. The procedure of settlement of conflicts is treated in detail. It comprises general settlement principles which are wider than a code of criminal procedure. Finally controversies related to rank in the order are treated.

The English translator of the Vinaya states that in respect of the causes for exclusion of penalty "all are remarkable for their humane and lenient tone, for their reasonableness and common-sense". This may count for all other Vinayaprovisions. 